\title{
Characteristics of Stratum Structure and Fracture Evolution in Stratified Mining of Shallow Buried High-Gas-Thick Coal Seam by Similarity Simulation
}

\author{
Qin Guangpeng $\mathbb{D}^{1,2}$ Cao Jing $\mathbb{D}^{3},{ }^{3}$ Wang Chao, ${ }^{1,2}$ Wu Shuo, ${ }^{1,2}$ and Zhai Minghua ${ }^{4,5}$ \\ ${ }^{1}$ College of Resource, Shandong University of Science and Technology, Tai'an, Shandong 271000, China \\ ${ }^{2}$ National Engineering Laboratory for Coalmine Backfilling Mining, Shandong University of Science and Technology, Tai'an, \\ Shandong 271000, China \\ ${ }^{3}$ College of Finance and Economics, Shandong University of Science and Technology, Tai'an, Shandong 271000, China \\ ${ }^{4}$ College of Energy and Mining Engineering, Shandong University of Science and Technology, Qing'dao, Shandong 266590, China \\ ${ }^{5}$ Shandong Energy Group Co., Ltd., Ji'nan, Shandong 250100, China
}

Correspondence should be addressed to Qin Guangpeng; skd992807@sdust.edu.cn and Cao Jing; 13954880579@163.com

Received 6 February 2021; Revised 5 August 2021; Accepted 27 September 2021; Published 10 November 2021

Academic Editor: Dayang Xuan

Copyright (C) 2021 Qin Guangpeng et al. This is an open access article distributed under the Creative Commons Attribution License, which permits unrestricted use, distribution, and reproduction in any medium, provided the original work is properly cited.

\begin{abstract}
The stratified mining of super thick coal seam is a process of repeated disturbance of the top roof, especially in the lower stratification, the upper complex rock layer has a greater settlement space, resulting in great changes in the strata structure and fissure distribution. The main coal seam thickness of Rujigou Coal Mine exceeds $20 \mathrm{~m}$, due to the high gas content of the coal seam, it is prone to spontaneous combustion, and the stratified mining method is adopted. When a small-size section coal pillar (less than $10 \mathrm{~m}$ ) is used, the complex rock structure evolution and fissure development characteristics during the stratified mining of shallow buried thick coal seam will directly affect the movement of gas transportation between the working face and the goaf and will directly affect the safety of the working face. Taking Rujigou coal mine as engineering background, this paper analyzes the breaking structure, fracture development, and evolution law of overlying strata in different layers and different sections of coal seam when the buried depth is shallow, and the extra-thick coal seam is stratified mining. The results show that in the process of stratified mining, the overlying strata break, in addition to the whole trapezoidal failure structure, will also form a local F type fracture structure, and with the stratified downward mining, the F type fracture structure will continue to move up and disappear until it is compacted. The " $V$ " type and " $U$ " type subsidence characteristics of different strata overburden are presented after mining in stratified working face of extrathick coal seam, and the subsidence amount is approximately symmetrical distribution along the middle line of goaf. In the mining process of the lower part of the layer, the end broken rock block is easy to slip along the hinge point by the hinged rock beam structure, and the sliding instability occurs. In the process of stratified mining of ultrathick coal seam, the main fissure of overburden is mainly longitudinal fissure, and it is very easy to form through with the upper layer and will finally connect with the surface under the condition of shallow buried depth. The inclined cracks connected with the adjacent goaf are formed above the coal pillar of the section, which becomes the passage of gas migration in the goaf. The research conclusion shows that for the stratified mining of high gas thick coal seam, special attention should be paid to the treatment of the gas on the stratified working face. In addition to the conventional gas treatment measures such as coal seam prepumping, the buried pipe pumping in the mining area can also be adopted, which can effectively reduce the gas concentration of the working surface.
\end{abstract}




\section{Introduction}

In the process of longwall face mining, the overlying strata collapse and break under the action of gravity after coal seam mining, thus, forming the overburden three zones. Among them, the collapse zone and fissure zone are good migration pathways of water, gas, and other fluids [1-3]. Stratified mining refers to the mining method by stratification that the low-angle dip thick seam sliced along the roof or the emergency inclined coal seam sliced along the elevation $[4,5]$.

Compared with the top coal caving mining, the stratified mining has features such as multiple disturbances, long mining cycle, and large actual extraction thickness of the coal seam, so the complex rock structure and complex rock fissure development have their unique places [6, 7]. Some scholars for example Han et al. [8] used electromagnetic detection, Y. et al. [9] used microseismic monitoring, Xiao et al. and Xin et al. [10, 11] used drilling hole monitoring, M.A. et al. [12] used similar simulation experiments, and Xiaoqian [13] performed theoretical analysis, the overburden rock strata fracture development progress and height was systematically studied of the thick coal seam.

Scholars at home and abroad have also carried out study an in-depth on the overburden rock strata movement and control technology, support pressure distribution, and fissure development characteristics under the repeated mining conditions of thick coal seam.

It has been systematically studied the surface settlement of thick coal seam under mountain [14] and thick loose layers conditions [15-17]. The influence of the mining depth, extracted coal thickness, mining times, and lithology of rock to activation coefficient [18-20] were explored. The subsidence coefficient expression of the surface and inside the rock layers was derived [21]. It is also proposed that the void part in the overburden rock strata damage zone during coal seam mining is converted to surface subsidence. During stratified mining, the neogenic fissure is small, and the old cracks will be closed, so the surface subsidence volume increased $[22,23]$.

Yonghua, Xiao and Xin $[10,11,24,25]$ studied the failure patterns and characteristics of the overlying strata by repeated mining of fully mechanized mining. The technique of controlling the failure height of overburden under stratified mining condition is proposed. Xianfeng et al. [12, 26] analyzed the roadway support principle and stratified mining strength of the stratified working face of the extra thick coal seam. Zeng et al. [13, 27] studied the fracture distribution characteristics of overlying strata after caving coal in huge thick coal seam in Zhundong Dajing mining area. It is suggested that the influence of coal caving stratification on aquifer disturbance is small. Sun and $\mathrm{Fu}[14,28]$ established the plane physics similarity simulation model, and it is clear that rock deformation is not an equivalent superposition under the influence of stratified repeated mining. Tang et al. [15, 29] studied the distribution of supporting pressure in two directions: direction and tendency of stratified mining of thick coal seam.
Taking Rujiigou anthracite company in Helanshan coalfield of NingXia Province of China as engineering background, this paper discusses the structure and fracture development law of overburden rock strata in multisection stratified mining of ultrathick coal seam under the condition of shallow buried mining. It will provide technical support for mine pressure control and gas disaster prevention.

\section{Engineering Background}

Rujigou Coal Mine is located in the southernmost tip of Rujigou exploration area in Helan Mountain coalfield, shown in Figure 1.

High and steep mountain slope, simple geological structure, few faults, extremely low aquifer permeability, and low water filling exist, and hydrogeological conditions of the mine are simple. The mine still has coal seam gas geological reserves of 1.17 billion $\mathrm{m}^{3}$, which are small coal seam gas field, and the reserve abundance is a high value.

The main mining coal seam is no. 2-3. The average thickness of coal seam is $18.09 \mathrm{~m}$, the original gas content is $21.77 \mathrm{~m}^{3} / \mathrm{t}$, and the original gas pressure is $0.45 \mathrm{MPa}$, which is stable high gas thick coal seam. The 010202 segment of the mine is located at the syncline axis of Rujigou. The buried depth is $100 \sim 300 \mathrm{~m}$, which is divided into five layers. The height of each layer is $3.6 \mathrm{~m}$, the strike length is $1550 \mathrm{~m}$, the inclined length is $236 \mathrm{~m}$, and the average coal seam inclination angle is $4^{\circ}$. The 010203 segment is adjacent to 010202 segment and which is divided into five layers too, and the height of each layer is $3.6 \mathrm{~m}$. Between the two segment, the coal pillar width is $5 \mathrm{~m}$. The surface of the two working faces is the surrounding open pit mine stripping slag storage platform, so the surface is relatively flat. The surface and layout of the working face are shown in Figures 2 and 3.

Under the influence of mine mining succession, the 010203 segment is set up as the distribution face of 010202 segment. One of the stratified working faces is to start mining after the third layer mining in 010202 segment, and then to the fourth layer of 010202 segment for mining. Therefore, because the coal seam is high gas coal seam, it is necessary to study the structure and fracture development law of overburden during stratified mining in 010202 section and the conduction law of overburden fissure and overburden fissure zone in $010203 \mathrm{sec}-$ tion, which is helpful to clarify the production process of gas prevention and take some technical measures.

\section{Simulation Model Construction and Monitoring Programme}

In the National Engineering Laboratory of Coal Mine filling and Mining of Shandong University of Science and Technology, the simulation test of similar materials is carried out to reproduce the process of stratified mining in the face of extra thick coal seam, and the characteristics of overburden structure change and fracture development are analyzed intuitively.

Within the scope of mining field, the average inclination of coal seam no. 2-3 is only 4 degrees, and the area of 010202 


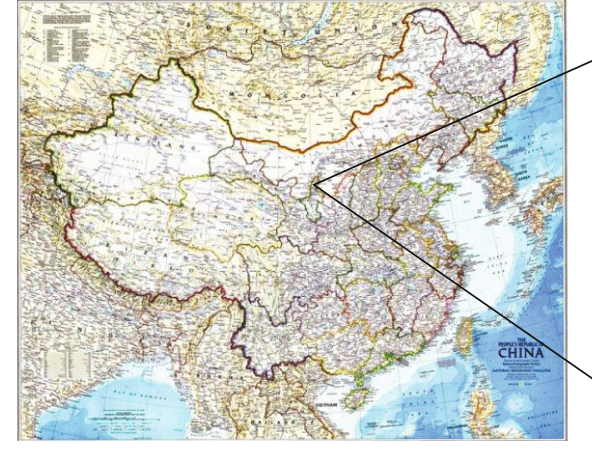

(a)

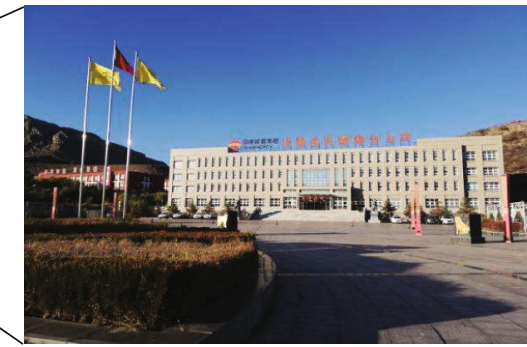

(b)

Figure 1: (a) Mine Location, Ningxia Province, China. (b) Panorama of the coal mine.
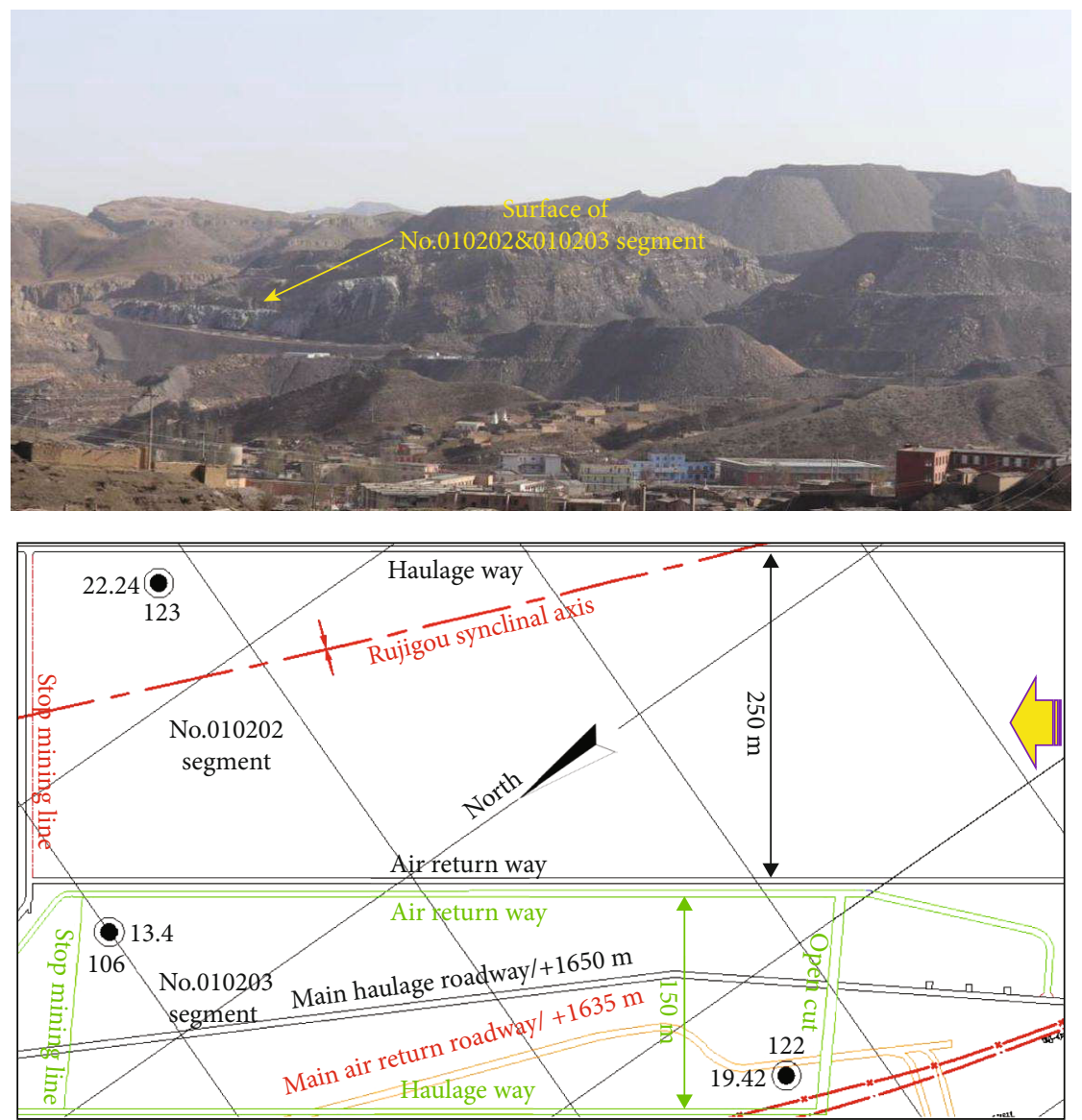

Figure 2: Layout of 010202 and 010203 segment in Rujigou Coal Mine.

and 010203 segment is near to the axis of Rujigou syncline, and the dip angle of the coal seam is smaller. Therefore, the formation is reduced to a near-horizontal formation during the establishment of a similar simulation model, which will not cause significant error to the research conclusion.

3.1. Similarity Simulation Model Establishment. The test platform is composed of frame system, test system, and displacement monitoring system. Southern NTS-332R4 total station instrument was used to record the displacement change of reflector. The migration law of overlying strata during mining with high definition digital camera monitoring model is shown in Figure 4.

3.1.1. Determination of Similarity Ratio of Model. The simulation of design similarity should follow the basic similar conditions such as geometric similarity, time similarity, bulk density similarity, elastic model similarity, strength similarity, and stress similarity. The similarity constants are determined as shown in Table 1 below.

3.1.2. Similar Material Modeling Process. In the early stage of the similar test model; the river sand is screened out; the 


\begin{tabular}{|c|c|c|c|c|c|c|c|}
\hline No. & Thickness (m) & Stratum & Composition & No. & Thickness (m) & Stratum & Composition \\
\hline 1 & 8.10 & $\begin{array}{l}\ldots \\
\ldots- \\
\ldots\end{array}$ & $\begin{array}{c}\text { Coarse } \\
\text { sandstone }\end{array}$ & 11 & 7.74 & 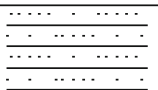 & Siltstone \\
\hline 2 & 8.30 & 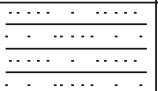 & Siltstone & 12 & 1.20 & 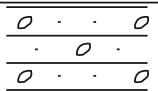 & $\begin{array}{c}\text { Sand } \\
\text { conglomerate }\end{array}$ \\
\hline 3 & 4.10 & $\begin{array}{llll}0 & \cdot & \cdot & 0 \\
\cdot & 0 & \cdot \\
0 & \cdot & \cdot & 0 \\
\end{array}$ & $\begin{array}{c}\text { Sand } \\
\text { conglomerate }\end{array}$ & 13 & 6.30 & 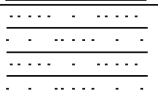 & Siltstone \\
\hline 4 & 3.0 & 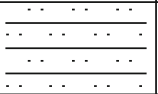 & $\begin{array}{c}\text { Middle } \\
\text { sandstone }\end{array}$ & 14 & 4.07 & & $\begin{array}{l}\text { Coal seam } \\
\text { No.2-1 }\end{array}$ \\
\hline 5 & 9.0 & 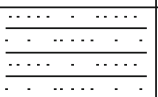 & Siltstone & 15 & 4.98 & 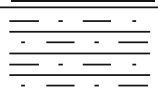 & $\begin{array}{c}\text { Sandy } \\
\text { mudstone }\end{array}$ \\
\hline 6 & 3.5 & 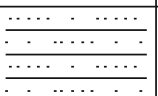 & $\begin{array}{c}\text { Middle } \\
\text { sandstone }\end{array}$ & 16 & 4.71 & & $\begin{array}{l}\text { Coal seam } \\
\text { No.2-2 }\end{array}$ \\
\hline 7 & 5.22 & 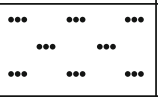 & Fine sandstone & 17 & 4.37 & 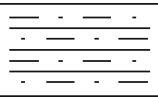 & $\begin{array}{c}\text { Sandy } \\
\text { mudstone }\end{array}$ \\
\hline 8 & 10.28 & 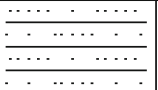 & Siltstone & 18 & 12.66 & & $\begin{array}{l}\text { Coal seam } \\
\text { No.2-3 }\end{array}$ \\
\hline 9 & 9.90 & 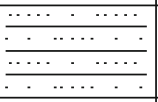 & $\begin{array}{c}\text { Middle } \\
\text { sandstone }\end{array}$ & 19 & 1.46 & 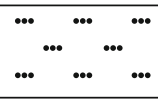 & $\begin{array}{l}\text { Fine sandstone } \\
\text { (dirt band) }\end{array}$ \\
\hline 10 & 7.07 & 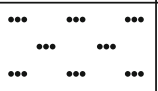 & Fine sandstone & 20 & 5.43 & & $\begin{array}{l}\text { Coal seam } \\
\text { No .2-3 }\end{array}$ \\
\hline
\end{tabular}

Figure 3: Comprehensive column diagram of the hydrogeology of the underlying strata.

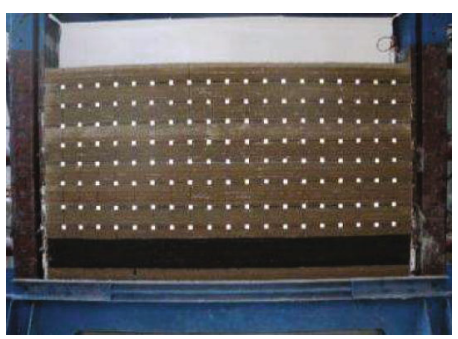

Test platform

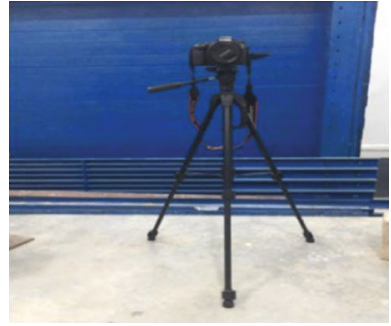

Digital camera

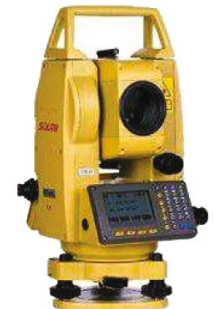

Electronic total station

FIGURE 4: Measuring and record equipment.

TABle 1: Similar parameters of the test model.

\begin{tabular}{|c|c|c|c|c|c|}
\hline \multicolumn{6}{|c|}{ Similar constant } \\
\hline $\begin{array}{l}\text { Geometry } \\
C_{l}\end{array}$ & $\begin{array}{l}\text { Bulk density } \\
\qquad C_{\gamma}\end{array}$ & $\begin{array}{c}\text { Time } \\
C_{t}\end{array}$ & Strength $C_{\sigma}$ & $\begin{array}{c}\text { Elastic model } \\
C_{E}\end{array}$ & $\begin{array}{c}\text { Poisson's ratio } \\
C_{\mu}\end{array}$ \\
\hline 100 & 1.5 & 10 & 150 & 150 & 1 \\
\hline
\end{tabular}

fixed channel steel is marked in proportion; the quality of river sand, quicklime, gypsum, and water is taken by electronic weighing; the weighing material is poured into the mixer and mixed evenly; and the matched material is poured into the similar simulation test frame, which is shown in Figure 5.

3.2. Monitoring Point Layout and Mining Method. When the similar simulation test bed is laid, after 3 days of natural drying, the baffle of the test bed is removed. According to the size of the test bed, ink lines with spacing of $10 \mathrm{~m} \times 10 \mathrm{~m}$ are arranged in the horizontal and vertical direction of the model surface, and all coal seams are blackened with ink. In order to observe the development law of overburden fractures more clearly, 8 displacement monitoring lines and 152 monitoring points are arranged in this model. The height of the measuring line from the roof of the coal seam is $8 \mathrm{~m}$, $18 \mathrm{~m}, 28 \mathrm{~m}, 38 \mathrm{~m}, 48 \mathrm{~m}, 58 \mathrm{~m}, 68 \mathrm{~m}$, and $78 \mathrm{~m}$; the interval between the measuring points in the horizontal and vertical directions is $10 \mathrm{~m}$; the mining step distance is also $10 \mathrm{~m}$; and the displacement observation is carried out by using the total station instrument, as shown in Figure 6. 


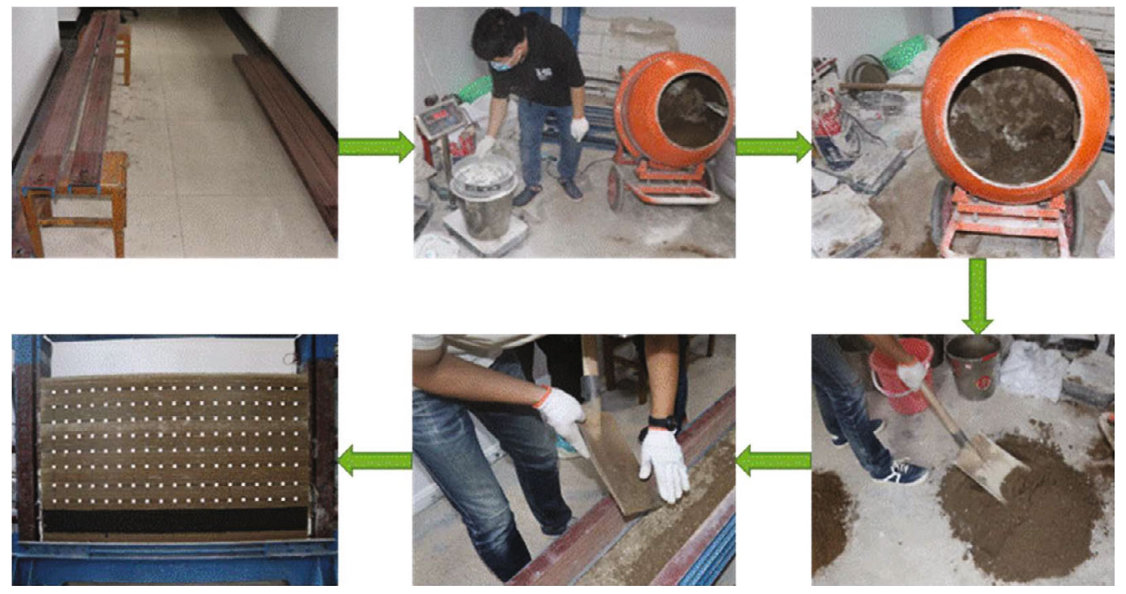

Figure 5: Similar material model laying process.

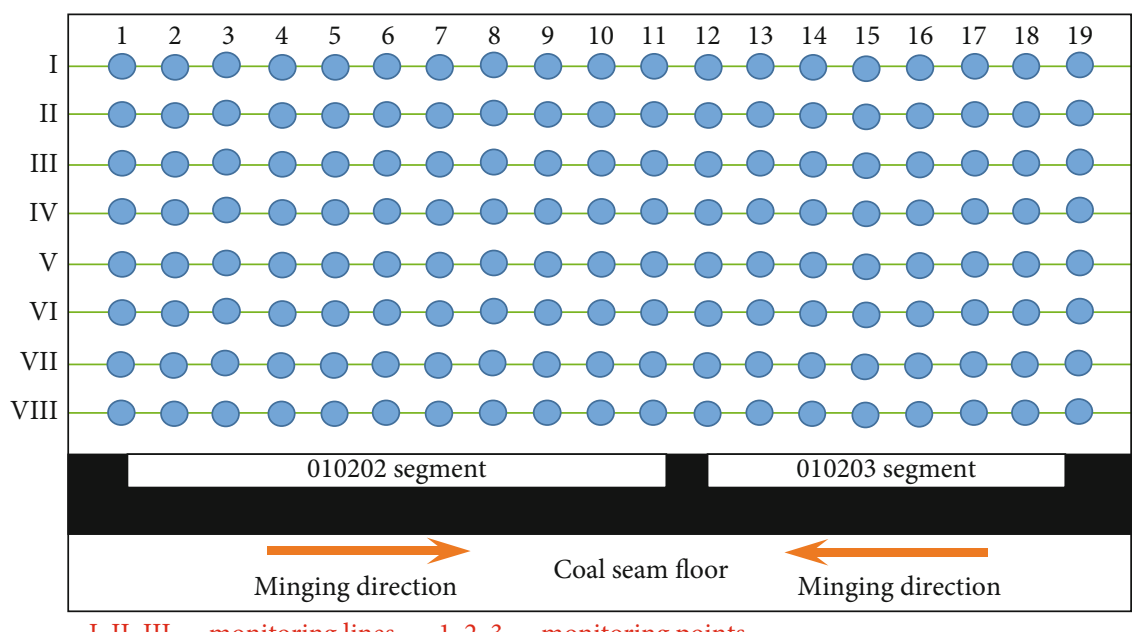

I, II, III.....monitoring lines $\quad 1,2,3 \cdots \cdots$ monitoring points

FIGURE 6: Schematic layout of monitoring points for similar test models.

\section{Overburden Structure Evolution under Stratified Mining Influence}

The simulated mining length of 010202 section is $90 \mathrm{~m}$, and the simulated mining length of 010203 section is $50 \mathrm{~m}$, which is affected by the test bench size. The sequence of coal seam mining is the first layer of 010202 section $\rightarrow$ the second layer of 010202 section $\rightarrow$ the third layer of $010202 \mathrm{sec}-$ tion $\rightarrow$ the first layer of 010203 section. Although affected by the size of the test bench, the length of the simulated excavation of the working face is only 90 and $50 \mathrm{~m}$, but through the analysis of the subsequent test results, the overlying strata have been fully mined after the excavation of the working face. Therefore, the research results will not appear too large error. There are 30 protective $\mathrm{m}$ at the left end of 010202 section and 25 protective $m$ at the right end of 010203 section. Since the cumulative mining height of the model is large, the super white glass plate of $2.4 \mathrm{~m} \times 0.8 \mathrm{~m}$ is covered on the front surface of the model before the simulated excavation to prevent the model from falling off the broken block. The simulated mining height of the model is $3.6 \mathrm{~m}$, and each mining cycle is $10 \mathrm{~m}$, waiting for the model overburden to migrate and stabilize before continuing the next mining. The interval is about $1 \mathrm{~h}-2 \mathrm{~h}$; during the excavation process, the high-definition camera is used to record the test phenomenon in time. Record displacement data with total station.

4.1. Fracture Characteristics of Overburden in the First Branch of Section 010202. When a stratified working face of 010202 segment is advanced to $30 \mathrm{~m}$, the overlying basic top is subjected to tensile stress, At this point, the direct top reaches the maximum suspended top distance, as shown in Figure 7(a). At $40 \mathrm{~m}$, increased direct top exposure, shear failure occurs when the tensile stress of the upper overburden exceeds the limit of rock strength, in the middle of the region. After breaking the two ends, the rock blocks are extruded to form a typical "masonry beam" hinged structure. At this time, the overlying strata collapse height is $8 \mathrm{~m}$, and fracture angle of rock formation is $51^{\circ}$. At $50 \mathrm{~m}$, the original "masonry beam" hinge balance was broken. To form a new articulated balance structure, the overburden fracture zone continues to develop upward and forms through fractures. There is a significant separation of the 


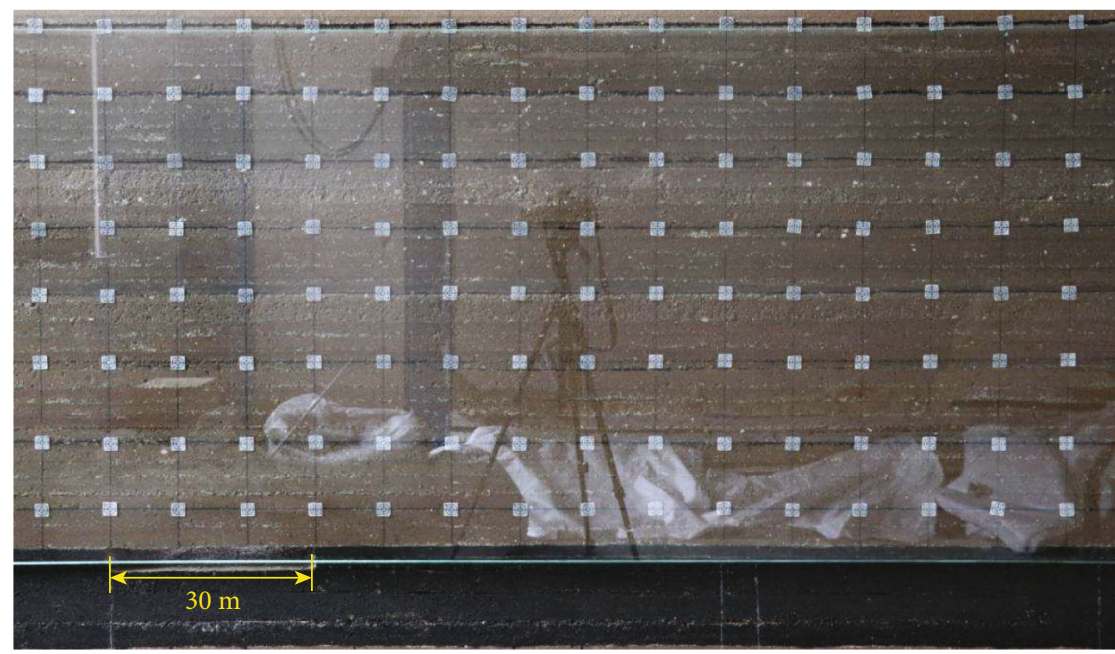

(a) $30 \mathrm{~m}$ of working face mining

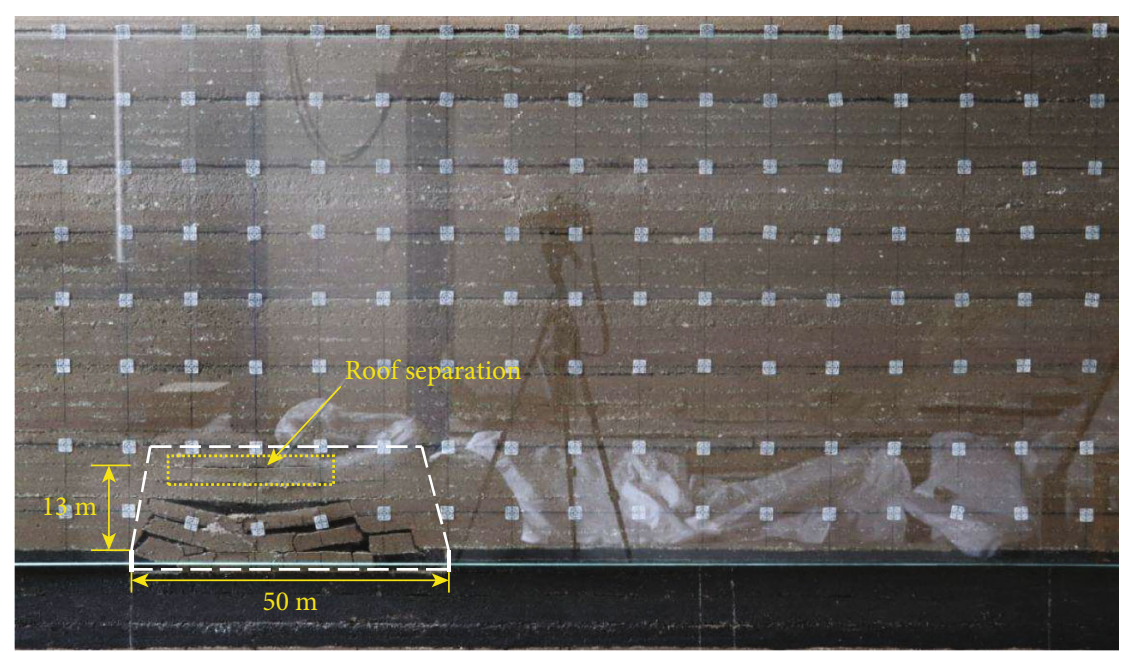

(b) $50 \mathrm{~m}$ of working face mining

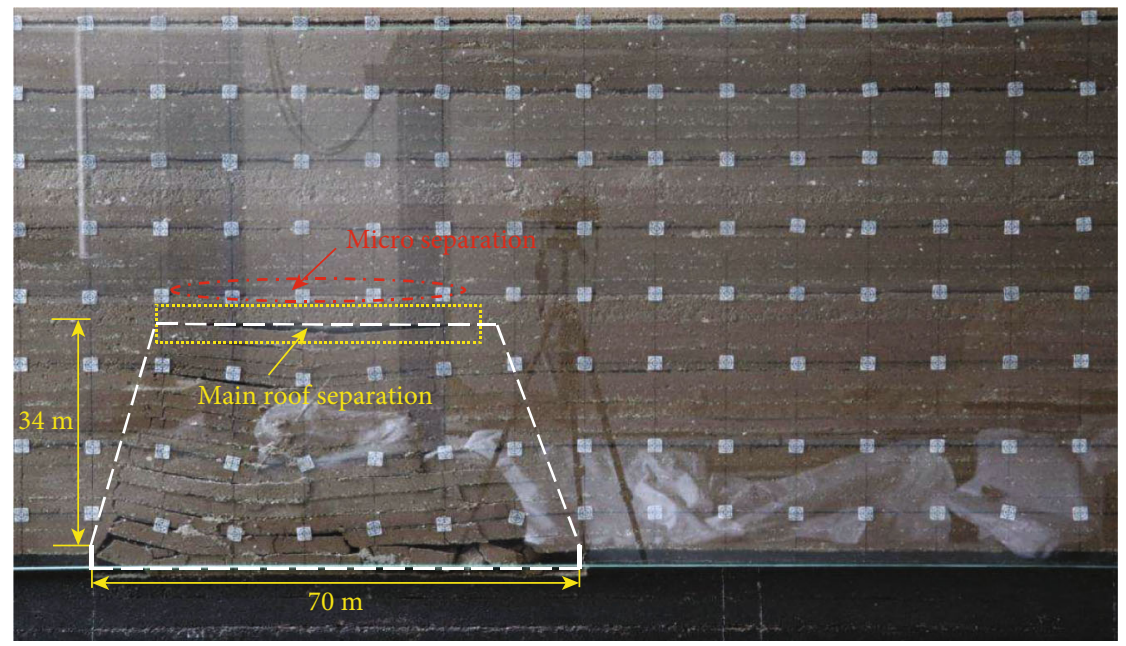

(c) $70 \mathrm{~m}$ of working face mining

Figure 7: Continued. 


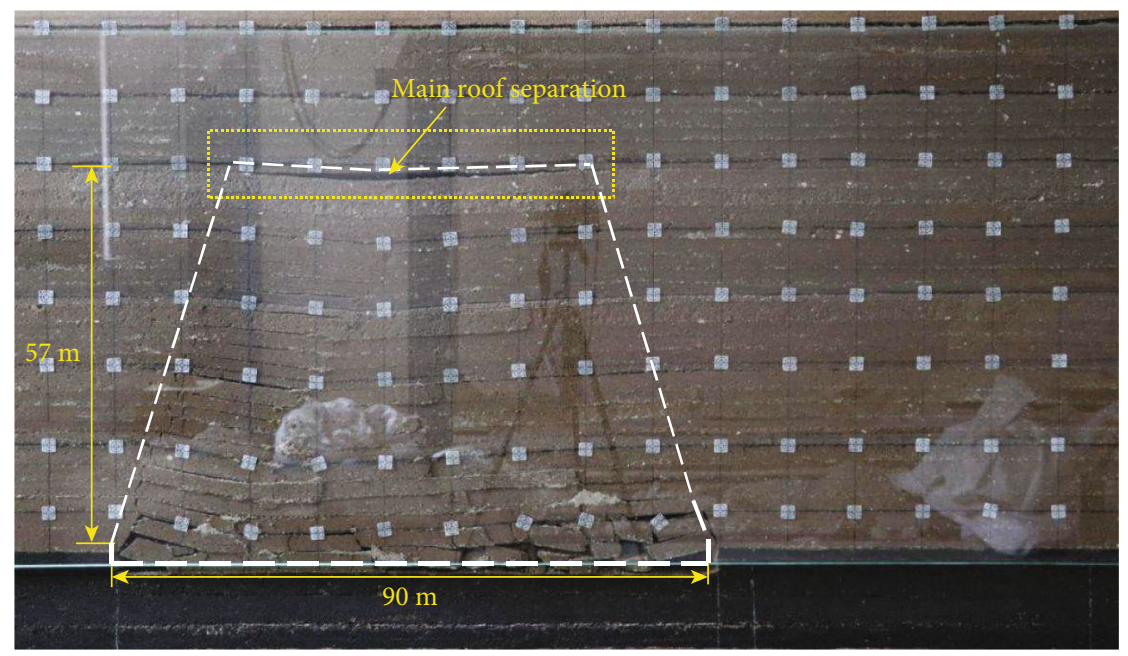

(d) $90 \mathrm{~m}$ of working face mining

FIGURE 7: Evolution of overburden structure in a first-layer working face in section 010202.

upper and lower key layers, from the height of the seam roof about $13 \mathrm{~m}$. Because of the formation of the separation layer, the lower low key layer is in a suspended span state, the direct top of the caving zone is in a regular breaking state, the cracks are widely distributed and have certain regularity, and the collapse form is shown in Figure 7(b). When the working face advances to $70 \mathrm{~m}$, the span distance of the low key layer increases further, the tensile stress exceeds the strength limit at the end of the support, and there is a significant fracture at the end. The fracture pattern is shown in Figure 7(c). When the working face is pushed to $90 \mathrm{~m}$, the thick rock overburden closest to the surface bends and sinks, and the height of the layer reaches $57 \mathrm{~m}$; because there are many overburden cracks near the coal pillar in the section of 010203 , the fault pattern of overburden is shown in Figure $7(\mathrm{~d})$.

4.2. Characteristics of Overburden Fracture in Secondary Mining in 010202 Section. The simulated mining height is $3.6 \mathrm{~m}$, and the simulated mining begins at $30 \mathrm{~m}$ on the left side of the model. When the advancing distance of the two-layer working face is $0-10 \mathrm{~m}$, the overburden gradually settles with the coal body of the two-layer; when the working face advances to $20 \mathrm{~m}$, there is a new fault line between the layers due to uneven rock subsidence near the opening hole; when advancing to $30 \mathrm{~m}$, the overburden tilts further to the high position and the hinge structure appears. The left rock block and the goaf side rock block squeeze each other, transfer horizontal force, overburden remains stable, and overburden break form is shown in Figure 8(a).

A new fault fissure is formed in the second layer working face to $40 \mathrm{~m}$, the fracture rock block rotates and sinks along the fault, and the height from the layer increases further. When the first layer is mined to $70 \mathrm{~m}$, the thick rock layer breaks for the first time and forms an articulated structure. When the second layer working face advances to $50 \mathrm{~m}$, a new fracture line appears in the high thick rock layer, which reduces the size of the thick rock block and forms a new hinged structure after stabilization.

The rock blocks that continue to advance to $60 \mathrm{~m}$, and thick strata continue to break and form hinged structures because of the increase of the length of suspension. After the fracture occurs in $70 \mathrm{~m}$, the overburden continues to sink along the fissure and the gap increases. The nearest thick rock layer is broken along the fault line.

When the working face is pushed to $90 \mathrm{~m}$, the cracks in the goaf are obvious. The height of the fissure above the nearest thick rock layer reaches the maximum, about $2 \mathrm{~m}$, and the main overburden also appears again, as shown in Figure 8(d).

4.3. Characteristics of Overburden Fracture in ThreeComponent Mining in 010202 Section. After the second layer is finished, the overlying strata are stabilized, the third strata of 010203 section continue to be mined, and the simulated mining height is still $3.6 \mathrm{~m}$. When the three-layer working face advances for $10 \mathrm{~m}$, the direct top continues to settle. When pushed to $20 \mathrm{~m}-30 \mathrm{~m}$, the hinged structure is destroyed, the original overburden is further broken to form small rock blocks and falls irregularly in the goaf, and the low key layer continues to sink. The original hinged structure is in quasistable state, as shown in Figure 9(a).

When the working face advances to $40 \mathrm{~m}$, the thick rock structure blocks turn and sink, the overlying strata also rotate and sink with the fault line, the fracture line becomes larger, and the fracture line is obvious. As shown in Figure 9(b), the slip rock is sinking along the fault line.

When the working face advances to $70 \mathrm{~m}$, the nearest thick rock layer from the surface is broken, then the lower layer is compacted, the overlying rock under the surface is deposited above the goaf, the coal seam overburden subsidence is more obvious, the mining fissure develops directly 


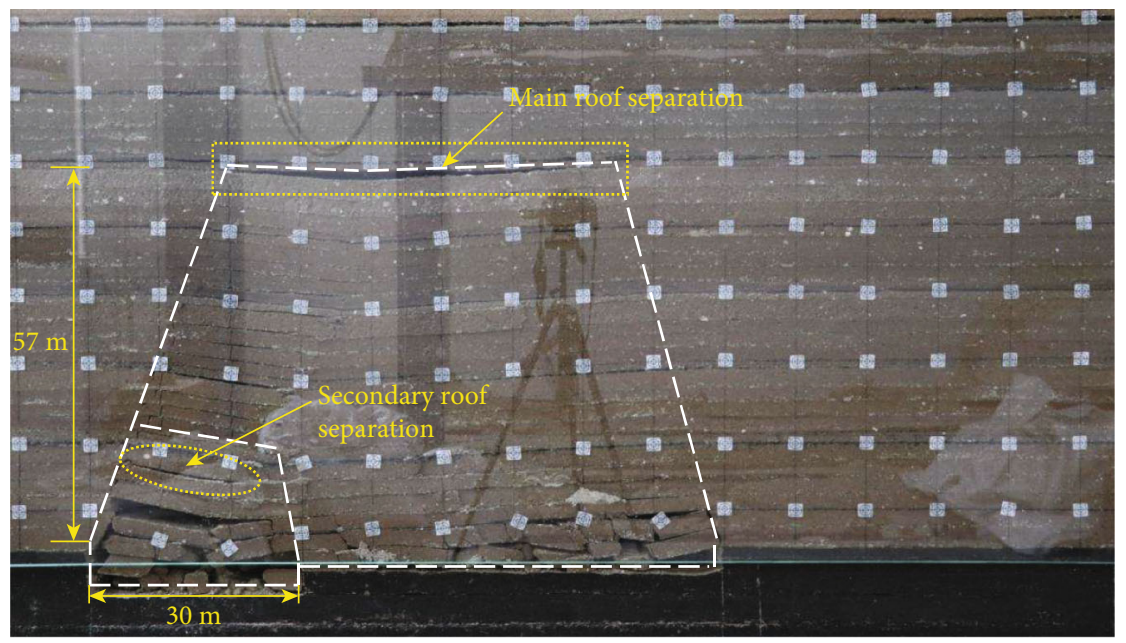

(a) $30 \mathrm{~m}$ of working face mining

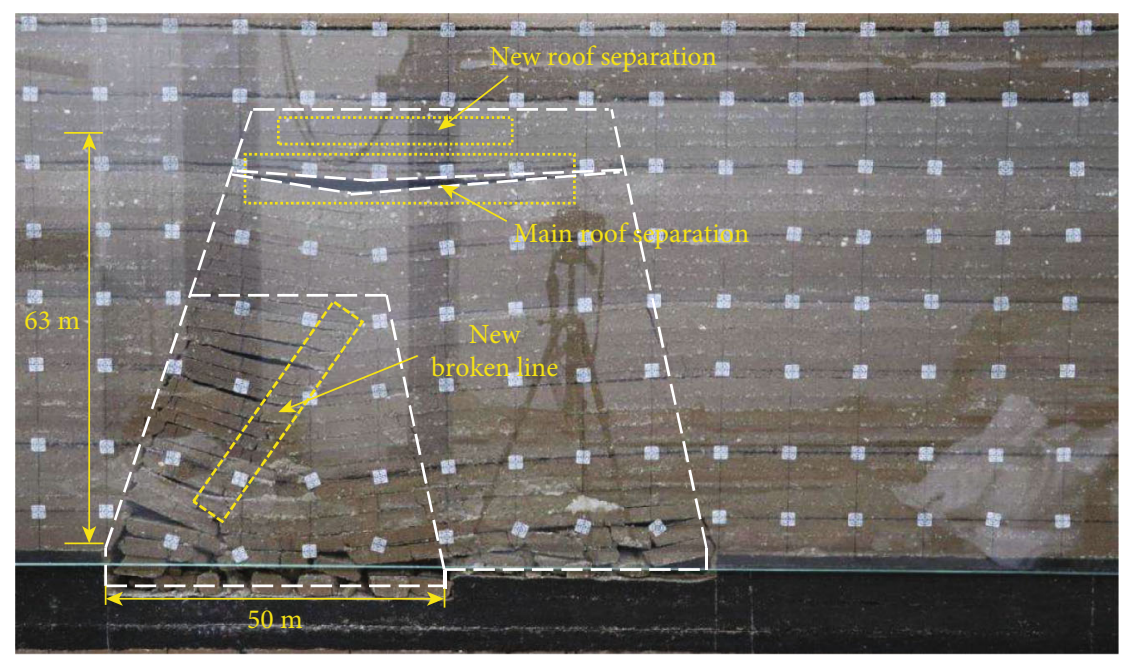

(b) $50 \mathrm{~m}$ of working face mining

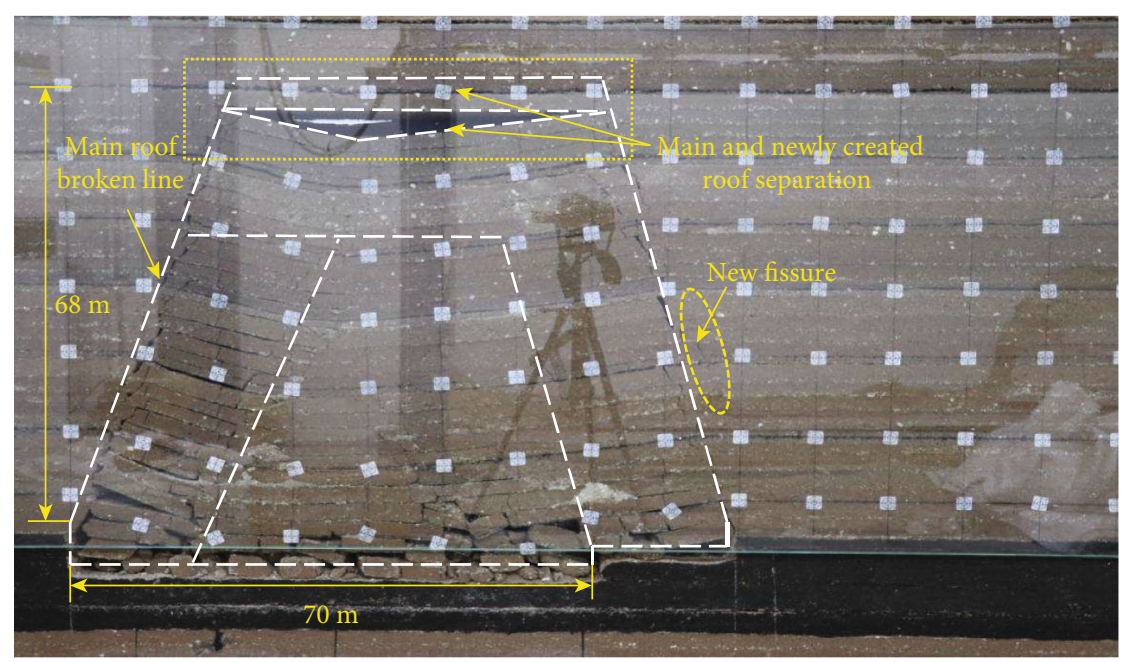

(c) $70 \mathrm{~m}$ of working face mining

Figure 8: Continued. 


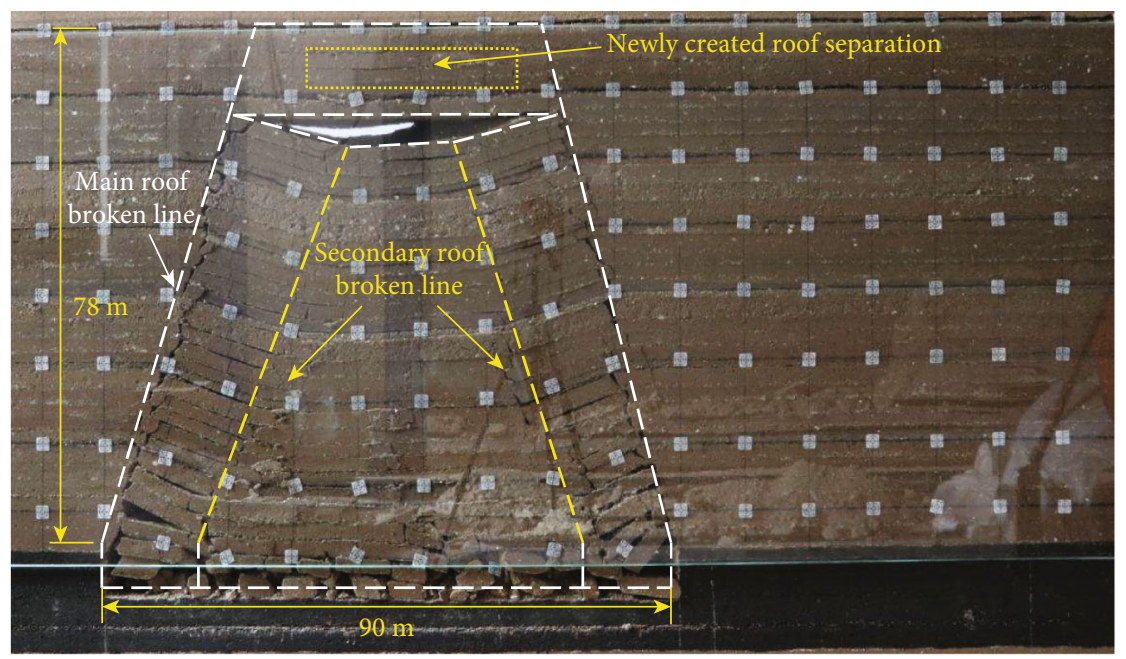

(d) $90 \mathrm{~m}$ of working face mining

Figure 8: Evolution of overburden structure in secondary working face of 010202 section.

to the surface, and the three mining overburden subsidence zones shift to the goaf center line.

The face has been pushed to $90 \mathrm{~m}$, overburden directly to the surface, trapezoidal caving settlement area has been formed above the coal seam, and the overburden in this area has been basically compacted. Affected by multiple mining, the end and middle double fault lines reach the surface, as shown in Figure 8(d).

4.4. Fracture Characteristics of Overburden in the First Branch of Section 010203. At the end of the mining in the 010202 section, the overlying strata are transported and stabilized, and the working face in the 010203 section is mined. The simulated mining height is $3.6 \mathrm{~m}$..

Before the first working face of 010203 section advances to $30 \mathrm{~m}$, the direct top of coal seam does not reach the breaking step distance, but the overburden does not break and collapse, but there are different degrees of separation between the overburden layers. However, in the coal pillar side of 010202 section near 010203 section, due to the influence of accumulative mining thickness and repeated mining, the overburden fracture line width is large. Under the influence of overlying rock pressure and self-weight, the overburden gradually forms tension crack. Characteristics of overlying strata failure movement during the first slicing mining in section 010203》 as shown in Figure 10(a)-10(e). When the direct top suspension area of the first layer working face is larger than the control top distance $40 \mathrm{~m}$, the overburden breaks and collapses in the goaf, the overlying strata appear with the separation layer, and the overlying strata are extruded to form a hinged equilibrium structure near the 010202 section. When a stratified working face is pushed to $50 \mathrm{~m}$, the overburden is normally broken, settled, and accompanied by delamination formation. The overburden collapse height is about $24 \mathrm{~m}$. The cantilever beam structure appears on the side overburden of the small coal pillar in the adjacent section, and the stress of the small coal pillar increases.
Due to the influence of large mining thickness and shallow buried depth on the engineering geological conditions of coal seam no. 2-3 in Rujiigou anthracite branch, when the section small coal pillar is used for stratified mining, the overburden above the goaf forms a positive trapezoid structure, and the fracture angle of the strata is between $74-78^{\circ}$. Compared with the fully mechanized caving mining method, the fracture angle of the strata increases slightly.

Synthesizing Figures 7-10, the F type local breaking structure will be formed in the positive trapezoid breaking overburden during the layered mining process, and with the downward movement of the mining stratification, the $\mathrm{F}$ type local breaking structure will gradually move up and slowly be compacted and disappeared. At the beginning of stratification in the adjacent sections, the cracks in the inverted trapezoid overburden above the coal pillar of the section are developed, and the cracks in the two mining sections are connected with each other.

On the other hand, it can be seen from Figure 10 that after mining in section 010202, the main fractures parallel to the goaf fracture line (such as Ma-F zone in Figure $10(\mathrm{c})$ ) and secondary fissures (such as Mi-F zone in Figure $10(d)$ ) are formed under the influence of overburden strata self-weight. Because of the small size of coal pillar, these fissures will easily communicate with 010203 section along its extension direction. At the same time, under the action of mining pressure, the fissures in small coal pillar will be very developed. Therefore, the small coal pillar will make the adjacent mining area easy to form a crack.

For the stratified mining of thick coal layer, the fissure development process of the overlying layer is different during the mining. The new fissure is created by the closure of the old fissure. Thus, some specific structures with stratified mining characteristics are formed such as the Fstrata structure. However, after the coal seam mining, the final fissure distribution in the overlying roof is not particularly related to stratified mining or the whole layer mining. 


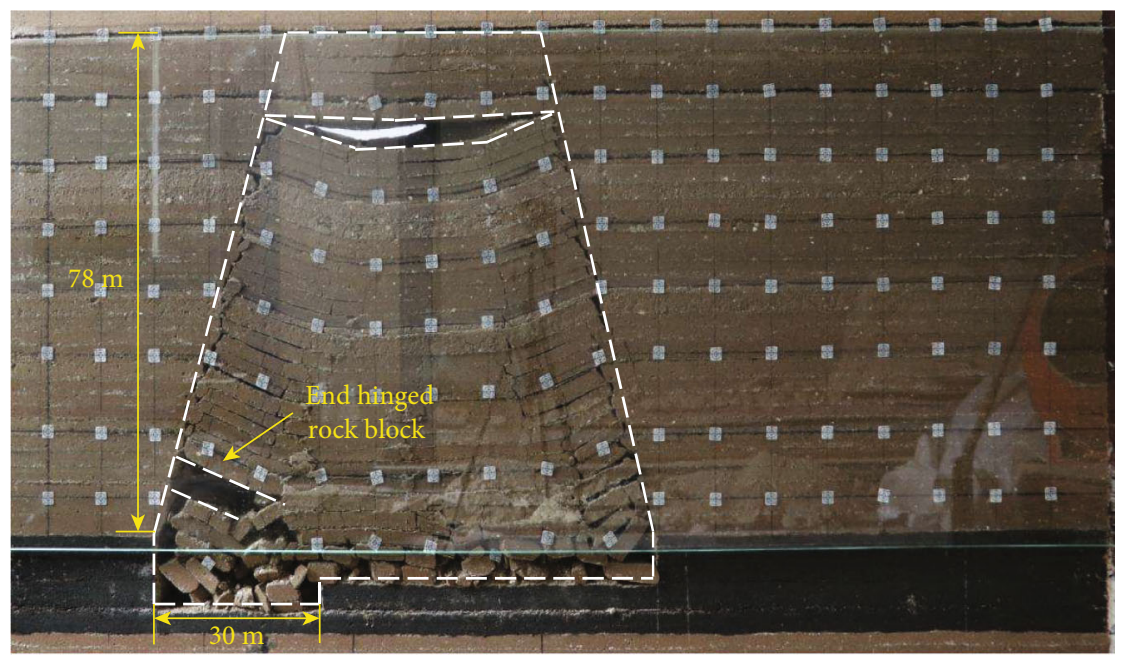

(a) $30 \mathrm{~m}$ of working face mining

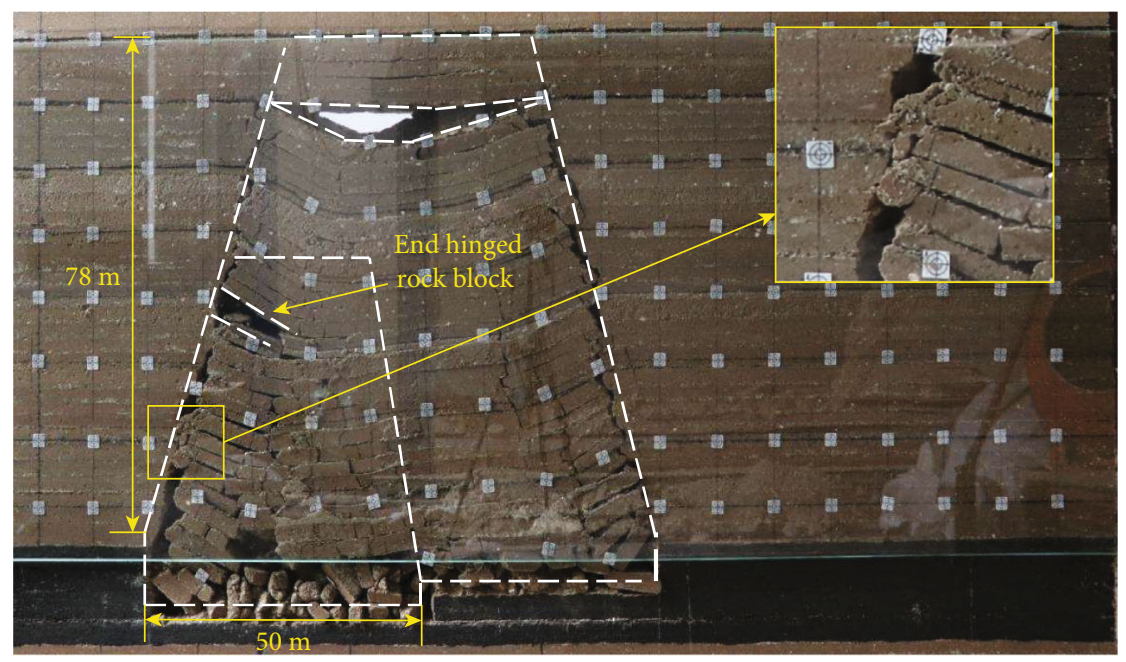

(b) $50 \mathrm{~m}$ of working face mining

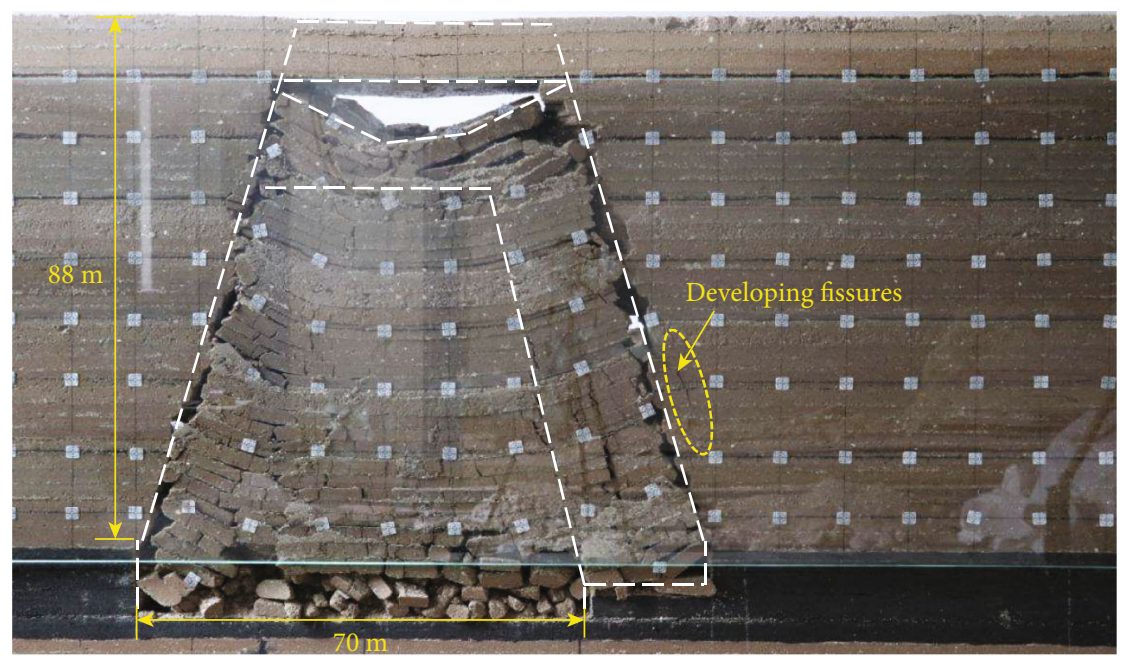

(c) $70 \mathrm{~m}$ of working face mining

Figure 9: Continued. 


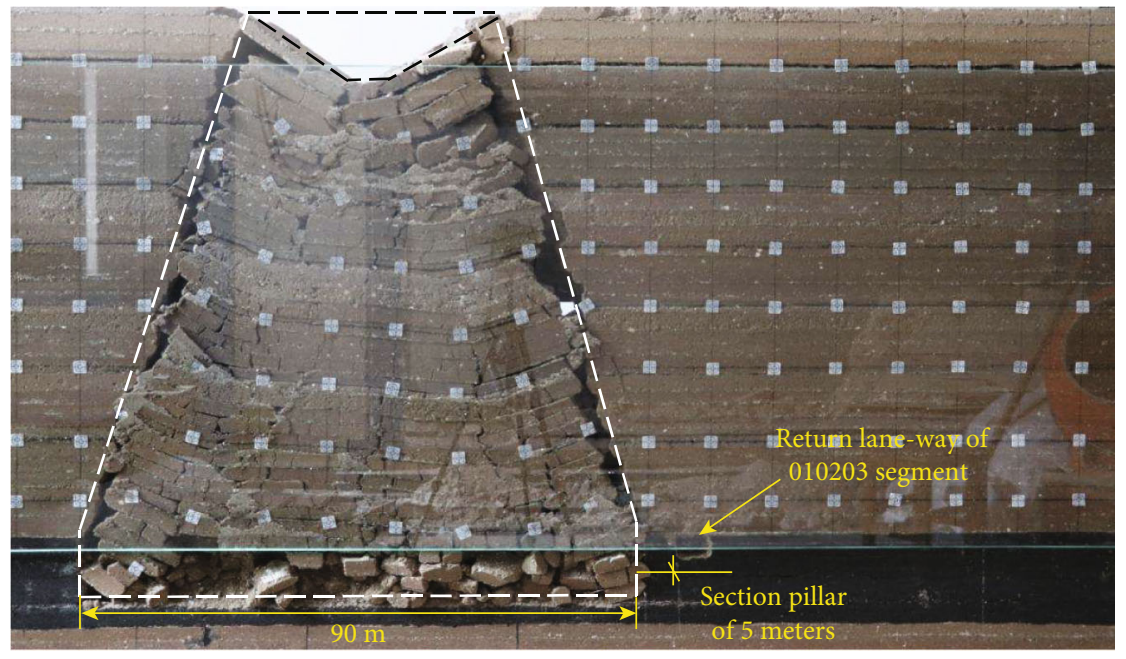

(d) $90 \mathrm{~m}$ of working face mining

FIgURE 9: Evolution of overburden structure in 010202 section.

\section{Migration and Fracture Conduction of Overburden in Multisection and Multilayer Mining}

5.1. Overburden Displacement in Stratified Mining of ExtraThick Coal Seam. Figures 11(a)-11(c) are the curve of rock subsidence during mining of 1-3 stratified working face in 010202 section. We can see from Figure 11(a) that after the first mining of the extra thick coal seam, the monitoring line is $\mathrm{I} \sim \mathrm{V}$ located in the overburden fracture zone area, where the vertical subsidence displacement of the no. 5 and no. 6 points on the monitoring line is the largest. With the time effect overburden separation area gradually compacted, the overburden deflection on both sides of goaf gradually becomes smaller, and the subsidence displacement also tends to become smaller, resulting in concave subsidence phenomenon, which generally shows a large displacement in the middle of goaf. The displacement on both sides of goaf gradually becomes smaller. Because the monitoring line $6 \sim 8$ is above the key layer, there is almost no displacement change and a stable structure.

Since Figure 11(b), after mining in the second coal seam working face, due to the influence of secondary mining, the fracture zone has broken overburden and broken twice. At this time, the monitoring line VI enters the fracture zone. The maximum displacement is $5.3 \mathrm{~m}, 5.2 \mathrm{~m}, 5.1 \mathrm{~m}, 5.0 \mathrm{~m}$, $5.1 \mathrm{~m}$, and $4.9 \mathrm{~m}$, respectively. At this time, the overburden strength above the coal seam decreases gradually, the overlying strata will slip and settle along the fault line, the overburden motion space will continue to increase, and the height of the fissure zone will further expand upward. Under the influence of the key layer, the monitoring line VII bends and sinks, and the displacement of the no. 7 point is maximum and the subsidence is $0.6 \mathrm{~m}$. There is no obvious change in the settlement VIII the monitoring line.

From Figure 11(c), after mining in the second layer of coal seam, affected by the third mining, the overburden fis- sure zone has been conducted to the surface, and the overburden above the coal seam and up to the surface has all settled, forming a subsidence basin. The maximum subsidence of overburden is distributed at $5 \sim 10$, the maximum value is about $11.2 \mathrm{~m}$, and the settlement of other measuring points in each line is approximately symmetrical. The I and II of the monitoring line reach the maximum displacement at the 15 th measuring point, which is close to the middle of the goaf of a stratified working face, with a maximum value of $3.0 \mathrm{~m}$, and a symmetrical distribution of displacement subsidence. There is no obvious change in the other measuring lines.

Through the above analysis, when the three-layer working face of 010202 section is finished, the model can simulate the coal seam thickness of $12.0 \mathrm{~m}$, which can describe the surface subsidence VIII the maximum subsidence is $9.61 \mathrm{~m}$, and the surface subsidence coefficient is 0.81 .

\subsection{Development Law of Overburden Fractures in Stratified} Mining. The mining end of the first layer working face in 010202 section, the overburden in the middle of the goaf is broken, 4 longitudinal fissures appear, the small fissures extend further, and the height of the fissures reaches $44 \mathrm{~m}$, as shown in Figure 12(a). As shown in the figure, at the end of mining in the second layer working face, five longitudinal fracture fractures are formed in the goaf, the cracks are obviously developed, the cracks are increased, and there are tiny separation layers between the strata and the strata, as shown in Figure 12(b). At the end of the mining, the width of the fracture increases further, as shown in Figure 12(c), respectively. At the end of the mining in the first layer of section 010203 , the direct collapse falls in the goaf, four longitudinal through fractures appear in the upper overburden fracture of the goaf, and the through cracks also evolve above the coal pillar and the coal pillar, as shown in Figure 12(d).

From the analysis conclusion of Figure 11, it can be seen that there will be several longitudinal fissures in the 


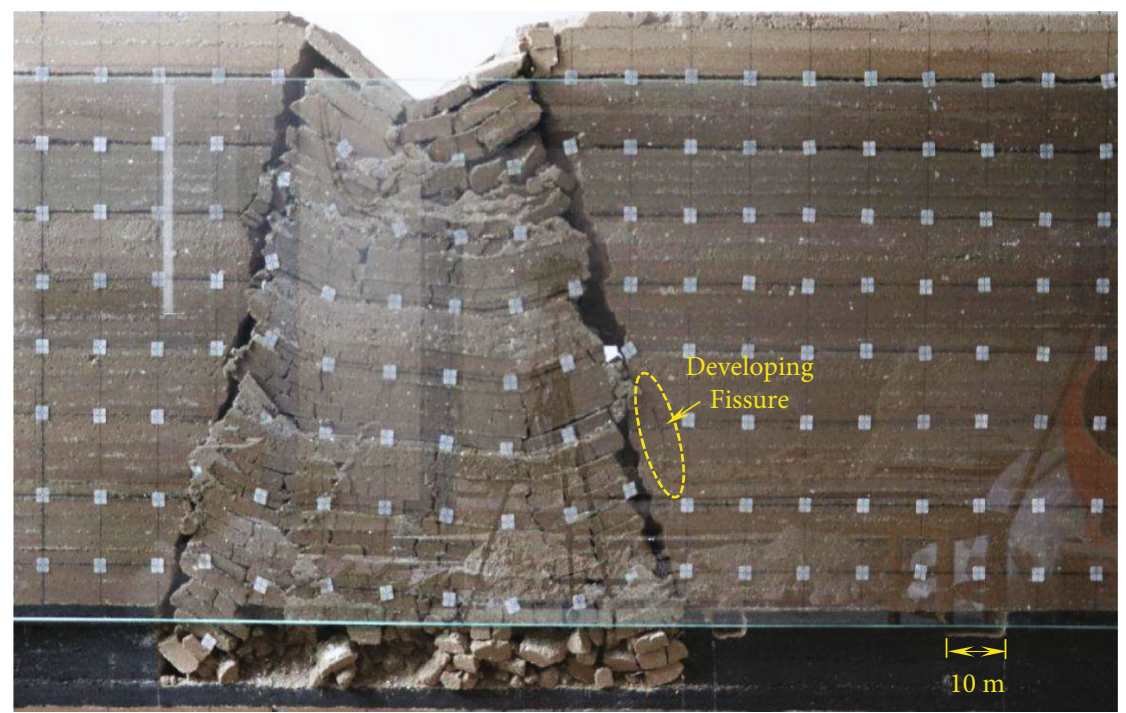

(a) $10 \mathrm{~m}$ of working face mining

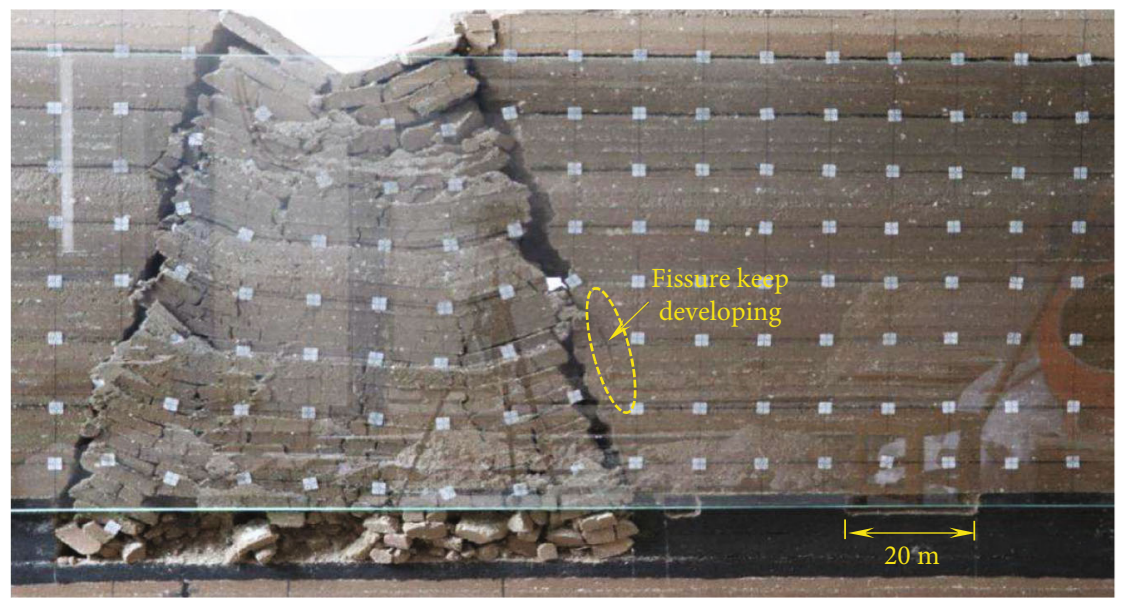

(b) $20 \mathrm{~m}$ of working face mining

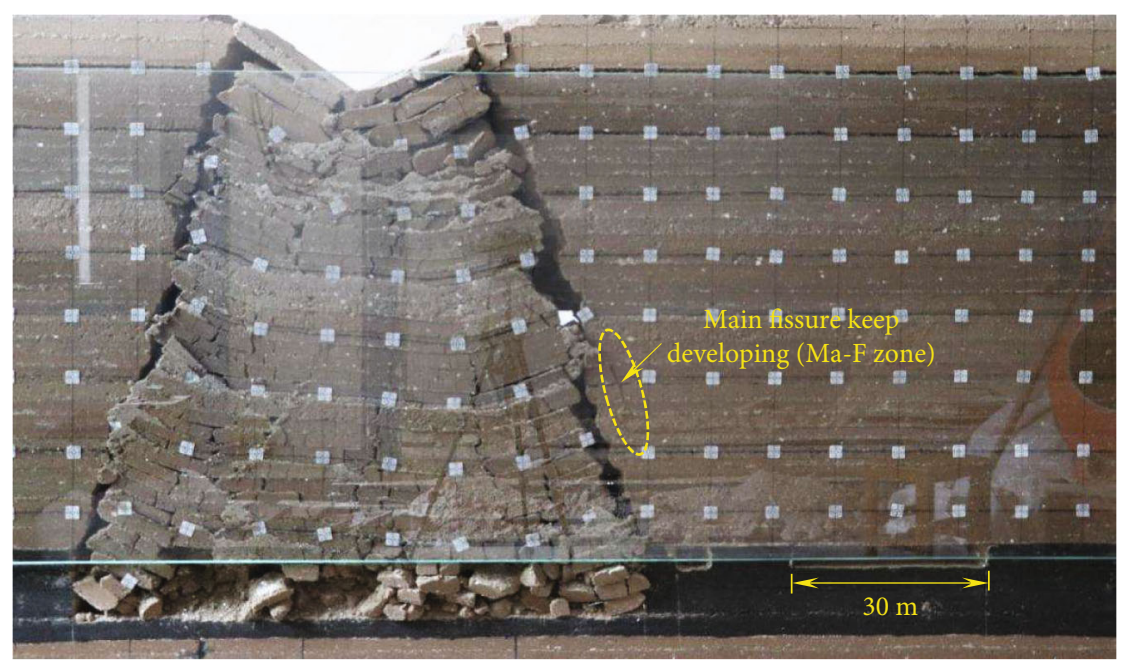

(c) $30 \mathrm{~m}$ of working face mining

FIgURe 10: Continued. 


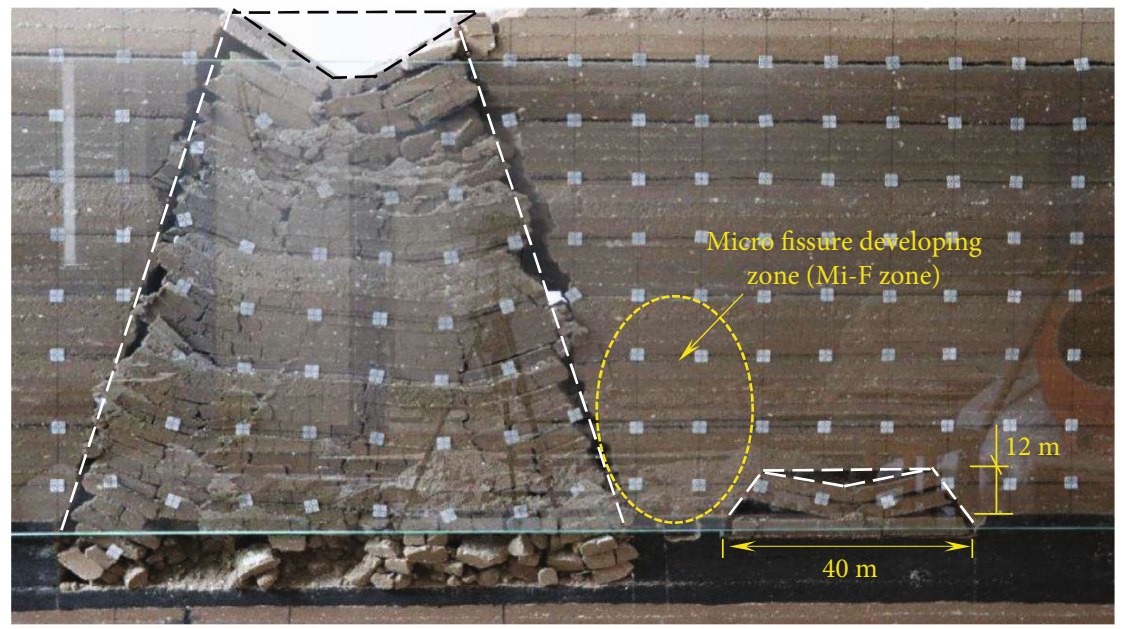

(d) $40 \mathrm{~m}$ of working face mining

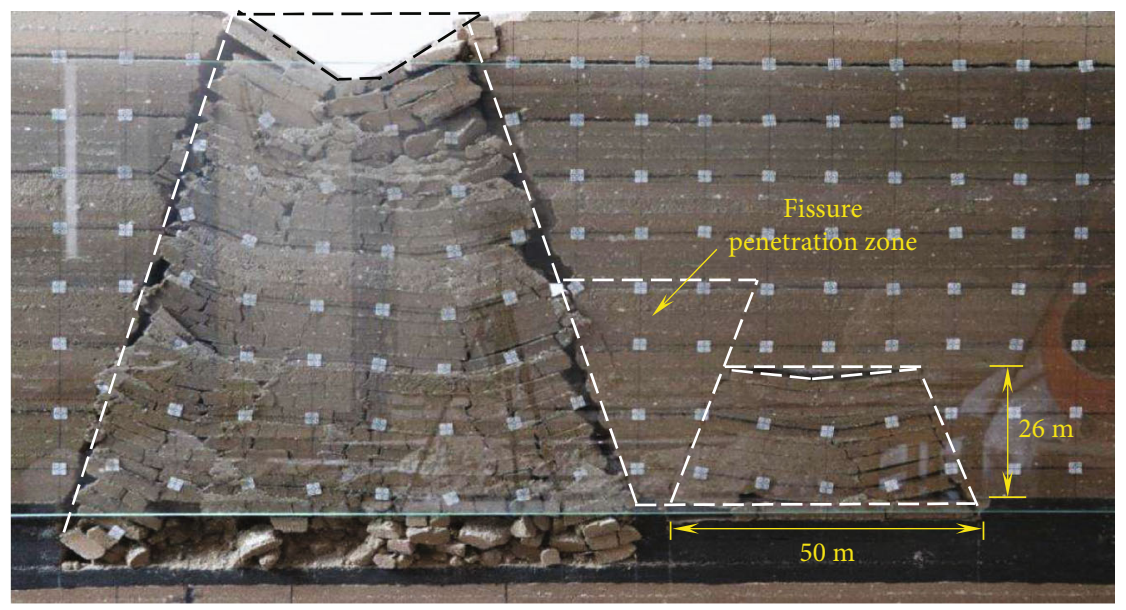

(e) $50 \mathrm{~m}$ of working face mining

FIGURE 10: Evolution of overburden structure in a first-layer working face in section 010203.

overlying strata during stratified mining of shallow buried extra-thick coal seam and will be connected with the upper layer and the final surface. In addition, when the small coal pillar is set up in the section, the vertical fissure connected with the adjacent goaf will be formed in the rock stratum area of the inverted trapezoid broken structure above the coal pillar, which will become the passage of gas migration in the goaf. Therefore, for high gas mines, it is necessary to consider the interval time of mining face when adopting section small coal pillar layout along empty roadway, so that this kind of longitudinal fissure is closed as far as possible before the production of working face.

\section{Technical Measures and Effect of Gas Prevention and Control}

6.1. Gas Extraction in Different Level Mined Out Area. It can be known from the engineering and geological situation of the mine, because of the working faces of 010202 and 010203 segment are cooperative mining, so the source of gas of 010203 segment will be very complex, especially the gas transportation path between adjacent goaf due to the existence of complex cracks in surround rock, so besides the conventional gas control measures, some special measures are necessary to develop gas treatment. With the stratified mining method, the height of the upper complex fissure zone changes continuously after stratified working face mining. And in addition, the coal seam deposit depth is shallow, so the traditional high pumping lane is unable to be arranged for gas extraction in the goaf area.

In order to effectively control the gas of 010203 segment, the air return way of the third stratification working face of 010202 segment is designed as a special gas control roadway. One set of large bore hole was drilled per $34 \mathrm{~m}$ near to the 010203 segment with steel pipe $(\Phi=600 \mathrm{~mm})$ to extract the gas in the 010203 segment goaf. The gas extraction hole layout is shown in Figure 13.

6.2. Analysis of the Extraction Effect. Through gas extraction in the first stratification working face of 010203 segment, according to the gas data monitoring results of 39 days from June 15 to July 23, the working face gas concentration, upper 

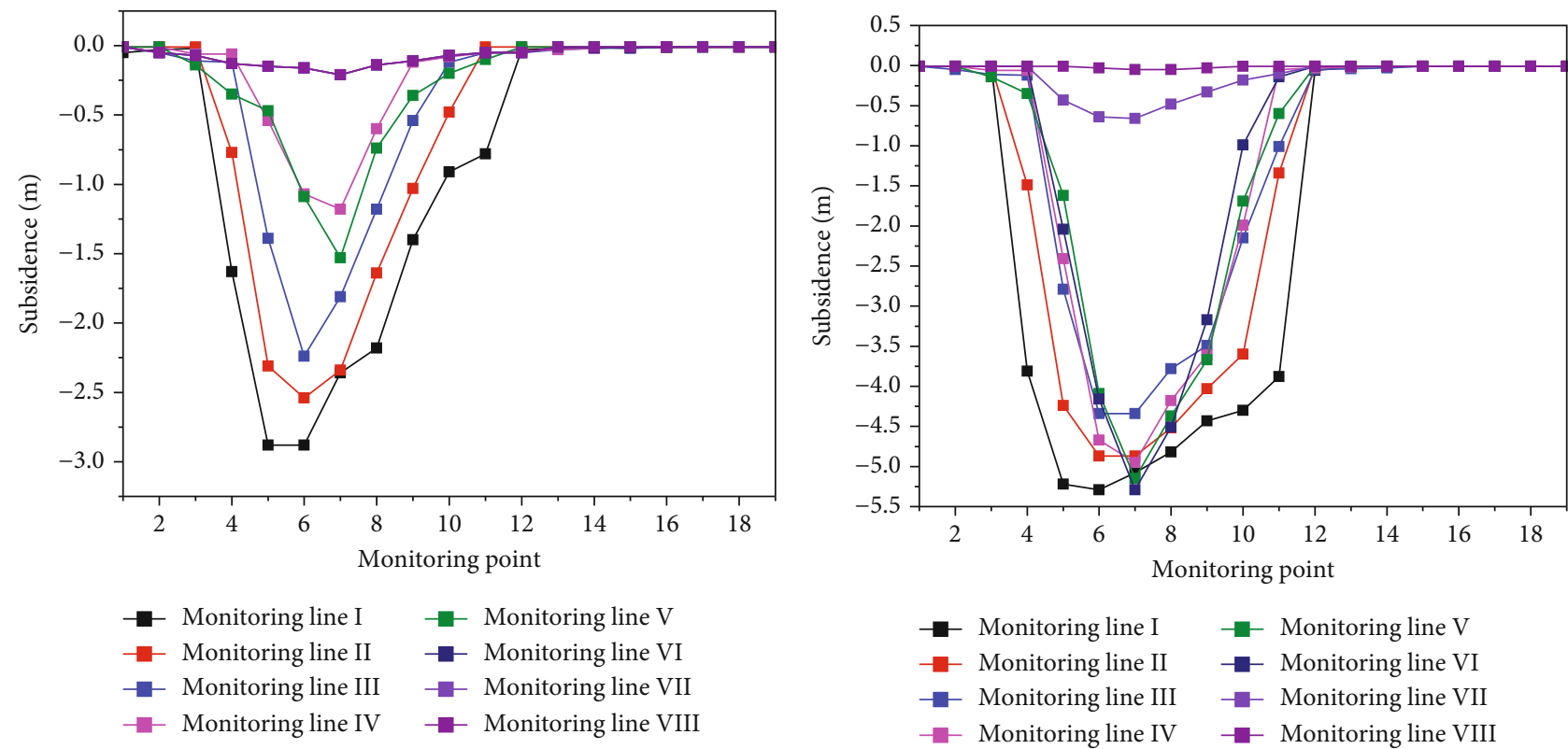

(a) Subsidence curve of first layer working face in 010202 section

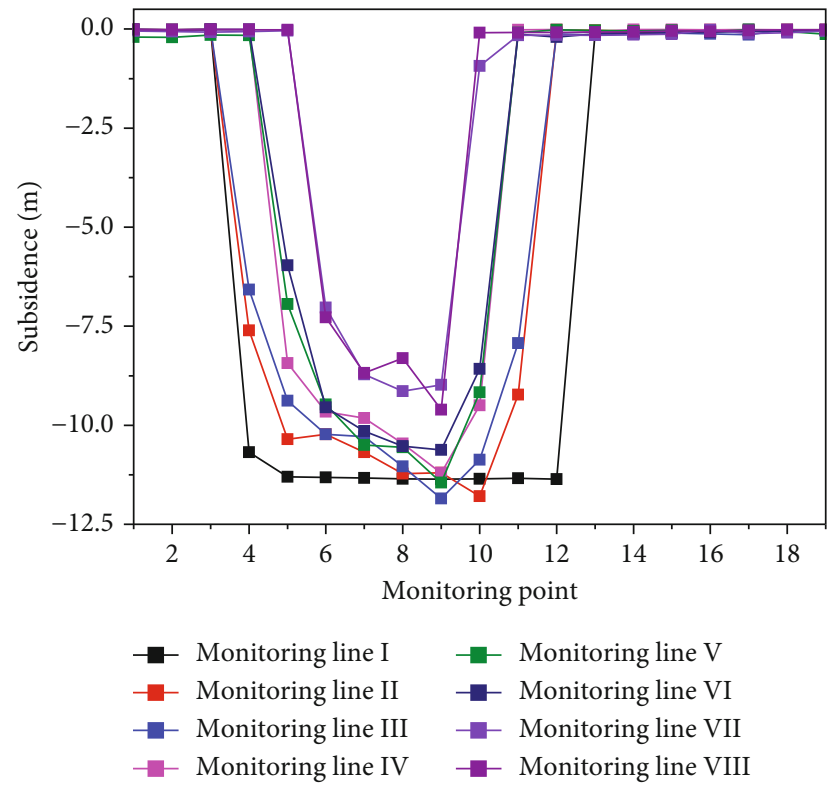

(c) Subsidence curve of third layer working face in 010202 section

(b) Subsidence curve of second layer working face in 010202 section

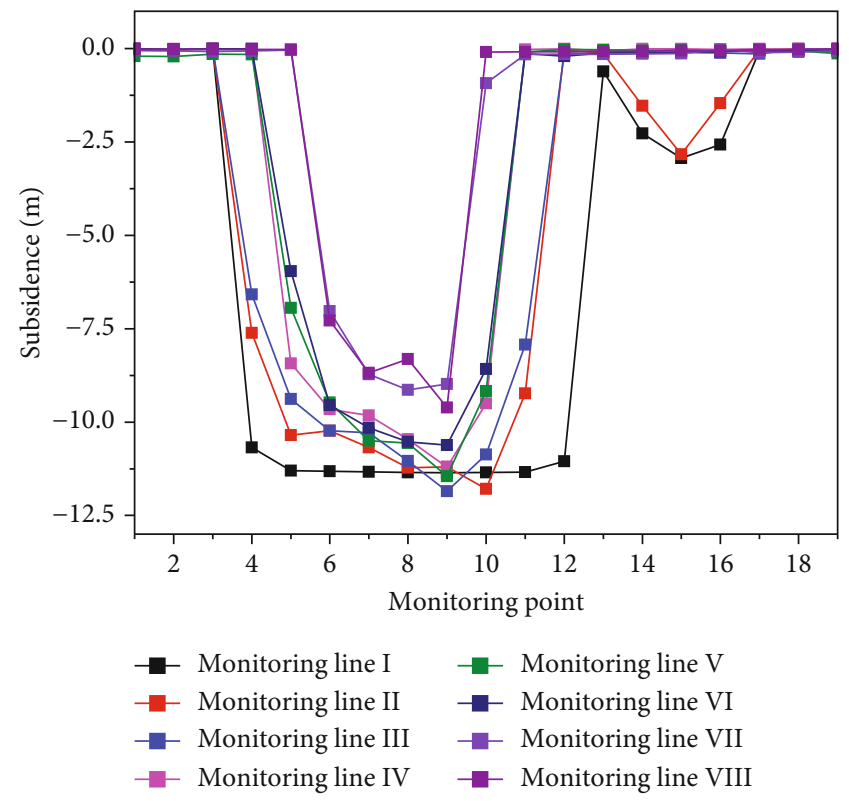

(d) Subsidence curve of first layer working face in 010202 section

FIgURE 11: Schematic diagram of overburden subsidence in stratified mining of thick coal seams.

corner gas concentration, and return lane gas concentration meet the regulations, and the working surface gas control effect is obvious. The change curve of gas concentration of working surface, upper corner gas concentration, and gas concentration of return airway is shown in Figures 14-16.

According to Figure 14, during the monitoring period, the maximum gas concentration of the working face is $0.46 \%$, the maximum average gas concentration is $0.106 \%$, the average gas concentration within 39 days is only $0.03 \%$, and the gas treatment effect is obvious, which can ensure the safe production of the working face.
According to Figure 15, during the monitoring period, the maximum gas concentration in single day in the upper corner is only $0.56 \%$, the gas concentration is greater than $0.5 \%$ is only once, the maximum average gas concentration in the single day is $0.28 \%$, and the average concentration of single day gas at the upper corner is only $0.23 \%$, which is far lower than the upper limit of $1 \%$ required in the Coal Mine Safety Regulations, which ensure sufficient safety factor in the production process.

According to Figure 16, the maximum gas concentration in single day in the return airway is $0.43 \%$, and the average gas concentration in a single day is only $0.05 \%$. The 


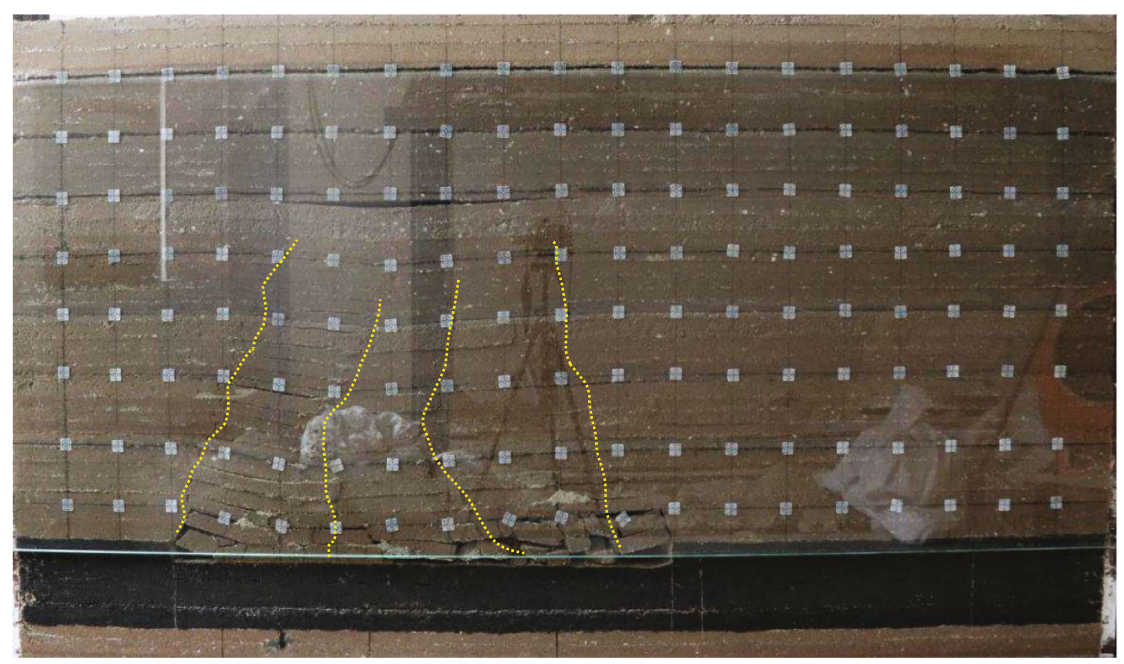

(a) Characteristics of mining fissures after the first layer excavation of section 010202

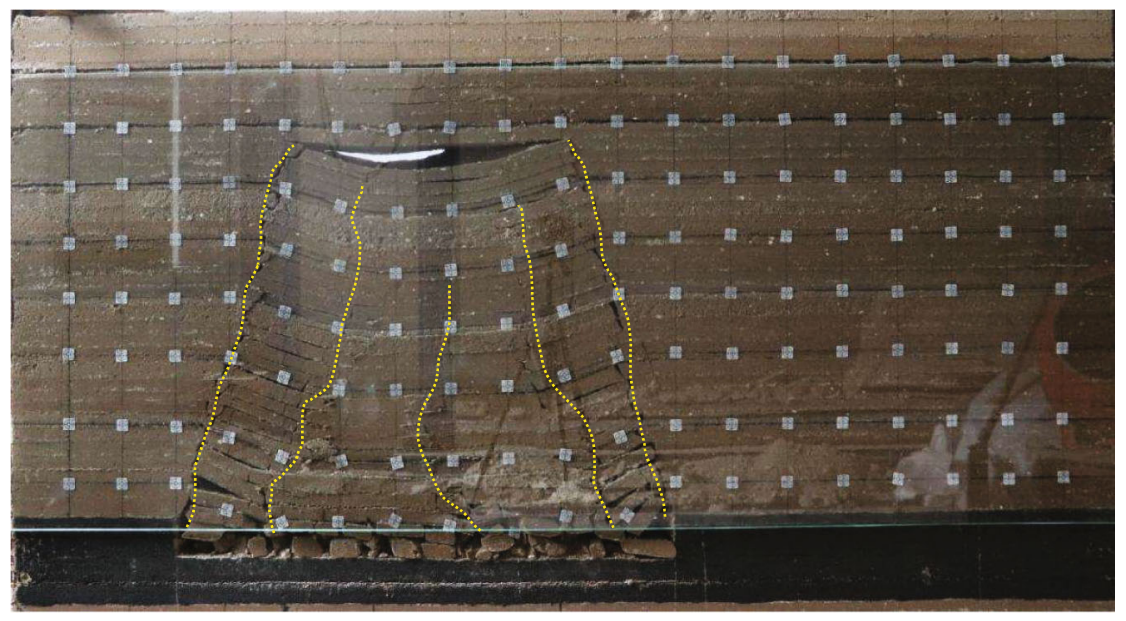

(b) Characteristics of mining fissures after the second layer excavation of section 010202

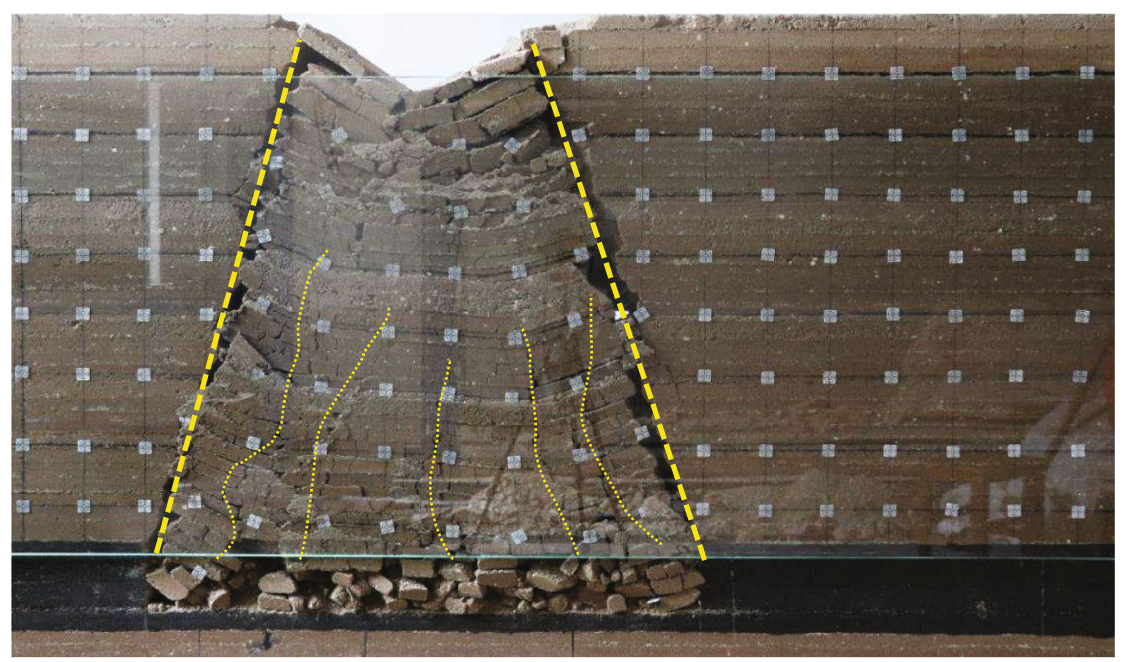

(c) Characteristics of mining fissures after the third layer excavation of section 010202

Figure 12: Continued. 


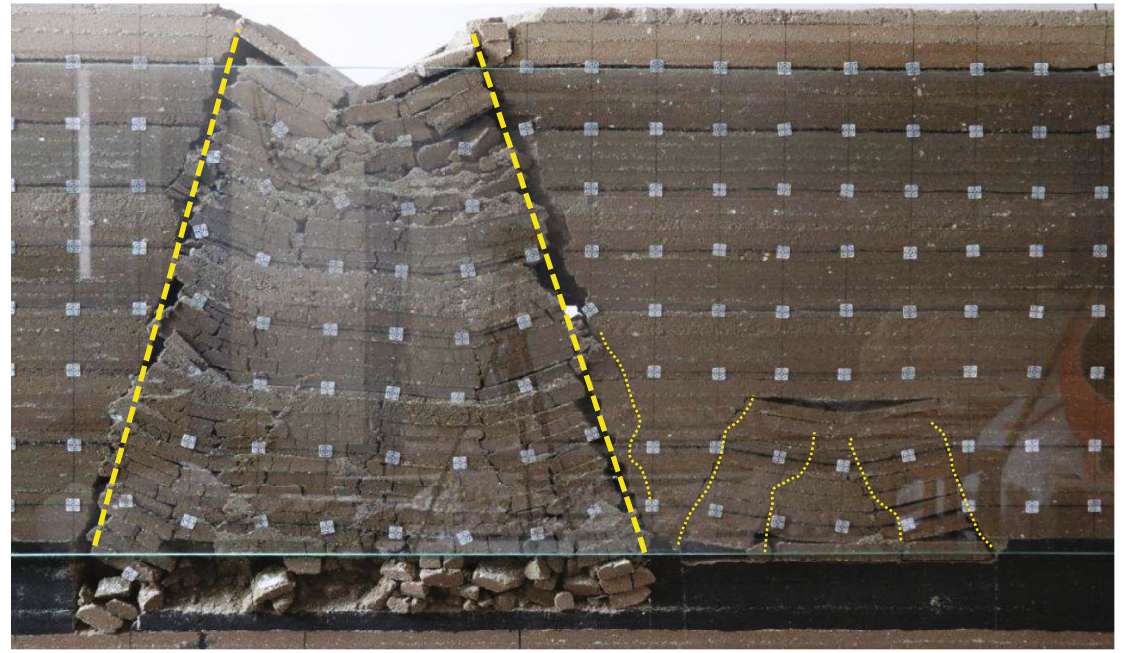

(d) Characteristics of mining fissures after the first layer excavation of section 010203

FIGURE 12: Fracture characteristics of overburden stratum in stratified coal seam mining.

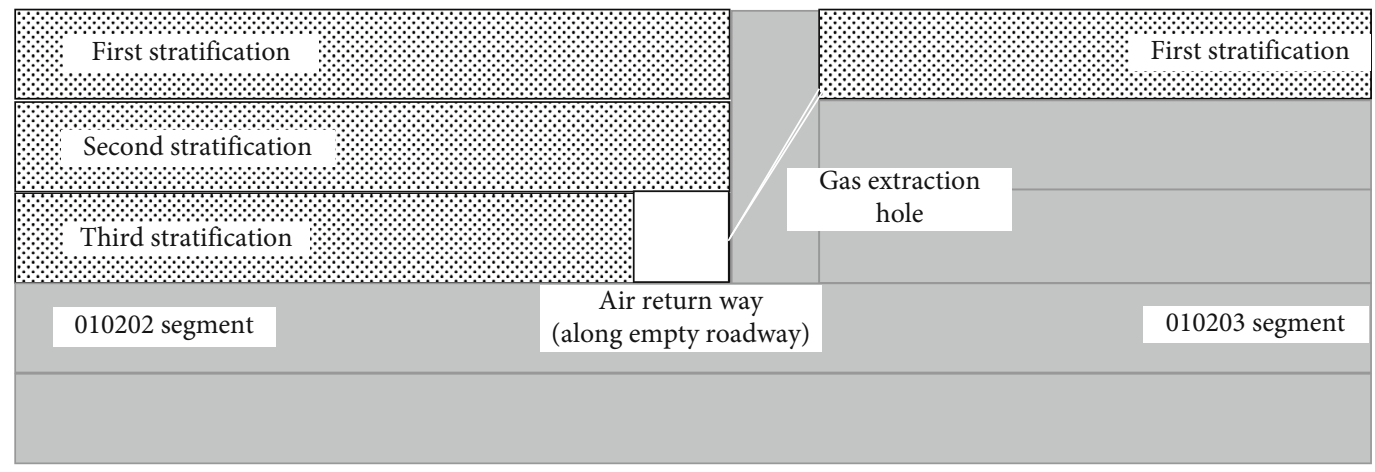

FIGURE 13: Layout of gas extraction in different level of mined out area.

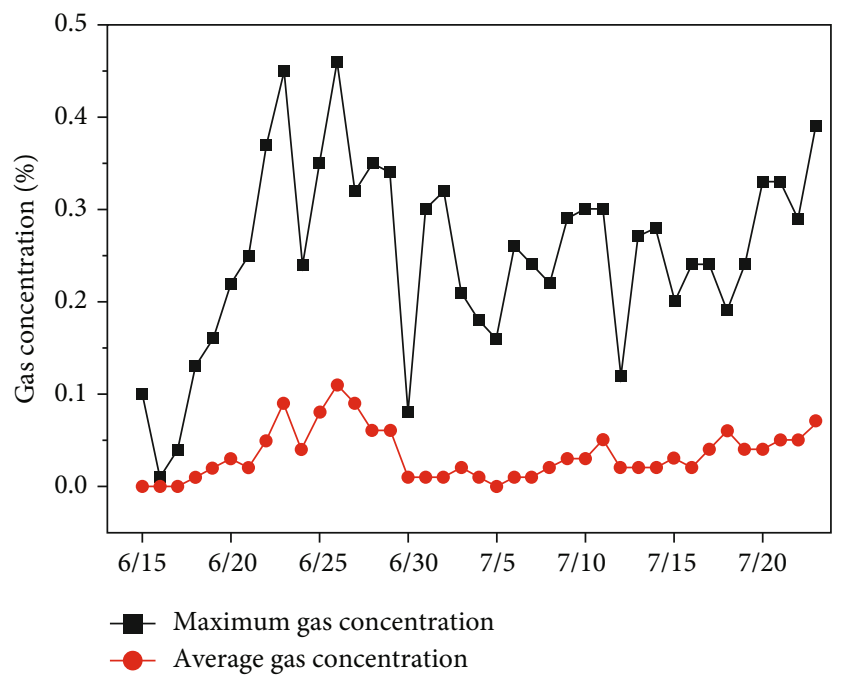

FIGURE 14: Curve of gas concentration in working face.

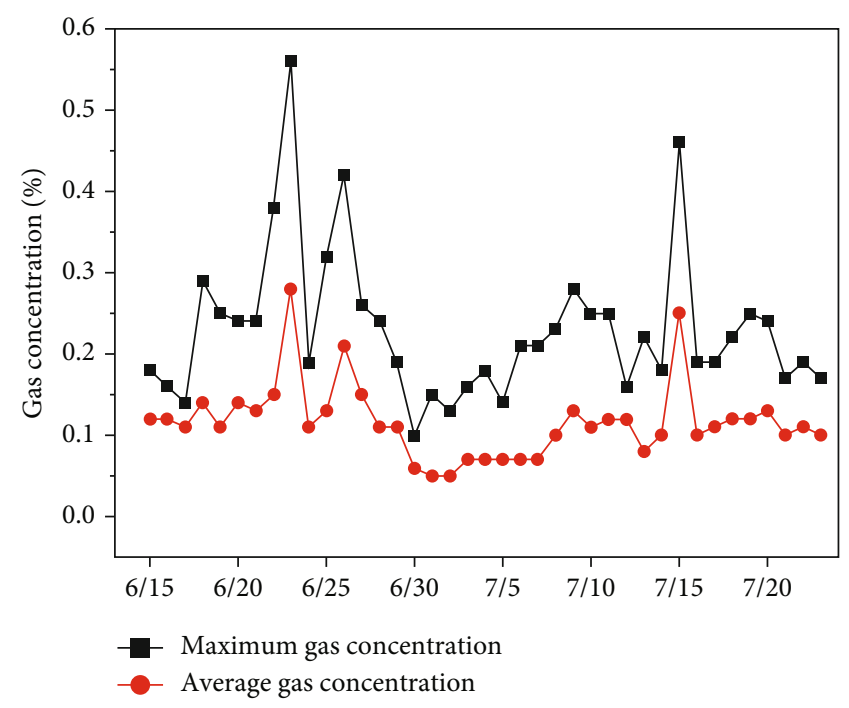

FIGURE 15: Curve of gas concentration in upper corner. 


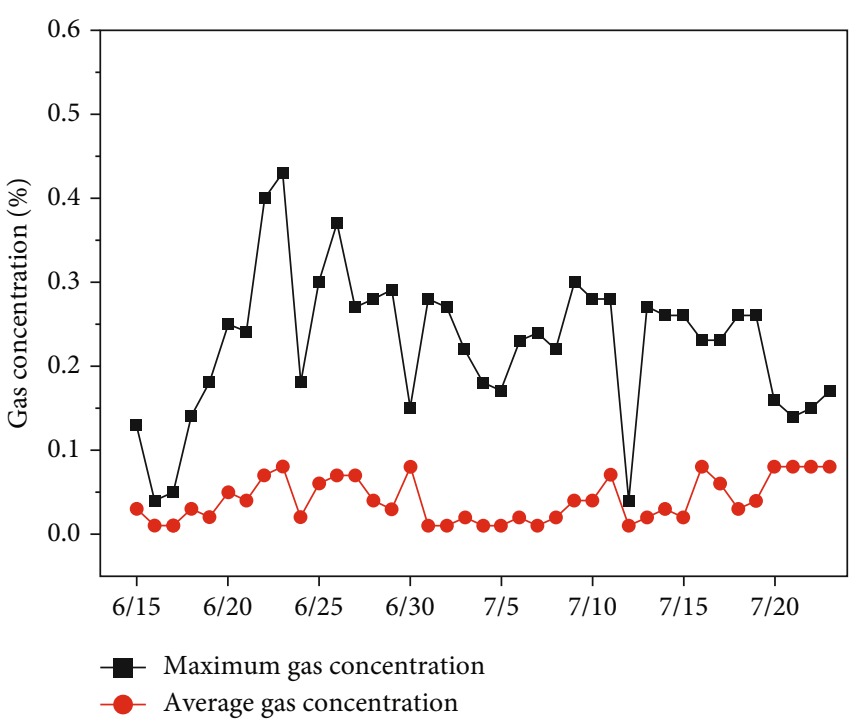

FIgURE 16: Curve of gas concentration in return air roadway.

monitoring data prove that the method of gas extraction in different level of mined out area can effectively improve the gas management level of high gas thick coal seam stratified working face.

\section{Main Conclusions}

(1) Under the condition of stratified mining of shallowly buried extra-thick coal seam, the overburden above goaf is easy to form a positive trapezoid structure, and a positive inverted trapezoid overburden structure is formed between adjacent sections. When the upper part is mined, the F type small breaking structure will be formed in the overburden structure of the positiveinverted-orth trapezoid. With the downward shift of the mining stratification, the $\mathrm{F}$ type small breaking structure will move up and gradually disappear

(2) After mining in the stratified working face of the extra-thick coal seam, the overburden rock of different strata presents the characteristics of "V" type and " $U$ " type settlement, with approximately symmetrical distribution. In the process of collapse, the end broken rock block is easy to squeeze each other to form hinged masonry beam structure, and the end overburden is more prone to slip along the occlusal point and slip instability during the lower layered mining

(3) In the process of stratified mining of extra-thick coal seam, the main fissure of overburden is mainly longitudinal fissure, which is easy to communicate with the upper layer, and will eventually connect with the surface under the condition of shallow buried depth. At the same time, the oblique crack connected with the adjacent goaf is formed above the coal pillar of the section, which becomes the passage of gas migration in the goaf
(4) According to gas extraction in different level of mined out area can effectively reduce the gas concentration in the process of working face production, which is an effective gas treatment method in the stratified mining of high gas thick coal seam

\section{Data Availability}

The data used to support the findings of this study are available from the corresponding author upon request.

\section{Conflicts of Interest}

The authors declare no conflicts of interest.

\section{Acknowledgments}

This study was sponsored by the Shandong Provincial Key R\&D Plan of China (Grant no. 2019SDZY034-1), the National Natural Science Foundation of China (Grant no. 51504145), and the Shandong Provincial Institute of Science and Technology Plan (Grant no. J17KB041). The authors are grateful for their support.

\section{References}

[1] L. Xiaoqin, A Study on the Mechanism of Water Inrush from Repeated Mining under Hard Overburden Strata, China University of Mining and Technology, Xuzhou, 2011.

[2] W. Zhenhai, "Voice frequency electric perspective and treatment technology for goaf water in upper seam of closedistance coal seams," Coal Engineering, vol. 48, no. 8, pp. $68-$ 70, 2016.

[3] L. Wenyong, W. Hu, and W. Baoyuan, "Gob air leak control technology of coal seam group at short range," Coal Technology, vol. 36, no. 9, pp. 160-162, 2017.

[4] G. Zhong-ping, W. Zhi-jie, and W. Fu-qing, "Study on improving upper limit in thick seams slicing mining under thick alluvium," Journal of China Coal Society, vol. 33, no. 11, pp. 1220-1223, 2008.

[5] D. Hua-yang, Y. Si-hai, G. Jun-ting, Y. Yue-guan, and L. Aijun, "Prediction method for surface movements and deformation induced by extra-thick steeply inclined coal seam horizontal slice mining," Journal of China Coal Society, vol. 38, no. 3, pp. 1305-1311, 2013.

[6] W. Yongping, "Research on strata behavior law of fully mechanized longwall caving mining face in extra thick seam in Datong mine area," Coal Mining Technology, vol. 36, no. 1, pp. 8-10, 2018.

[7] Z. H. A. N. G. Hongwei, Z. H. U. Zhijie, and L. J. Huo, "Lijie etc. overburden failure height of super high seam by fully mechanized caving method," Journal of China Coal Society, vol. 36, no. 4, pp. 544-550, 2011.

[8] J. Han, H. Zhang, Z. Gao et al., "Failure height of weak overburden by layered fully-mechanized mining in extremely thick coal seam," Journal of Mining \& Safety Engineering, vol. 33, no. 2, pp. 226-230, 2016.

[9] Y. Gui-liang, L. Qian, and W. Yuan-jie, "Study on mine pressure bumping prevention and control of slice mining in ultra thick steep inclined seam of deep mine," Coal Science and Technology, vol. 39, no. 2, pp. 17-21, 2011. 
[10] H. Xiao, W. Zhang, X. Wen, and B. Li, "Experimental investigation of floor rock permeability through injecting water in the slicing process," Journal of China Coal Society, vol. 25, no. 2, pp. 132-136, 2000.

[11] T. Xin, J. Zhenquan, C. Dingtao, and W. Zongsheng, "Determination of development height of water flowing fractured zone in thick seam slicing mining," Mining Safety and Environmental Protection, vol. 41, no. 6, pp. 44-47, 2014.

[12] M. A. Baoming, Z. Hong, and Q. Ziwei, "Determination of height of complex water guide fracture zone in stratified mining," Mining Safety and Environmental Protection, vol. 38, no. 6, pp. 54-56, 2011.

[13] S. Xiaoqian, J. Zhenquan, W. Zongsheng, and L. Yunjiang, "Height prediction of the "two zones" in shallow coal seam by slicing Ming," Mining Research and Development, vol. 35, no. 2, pp. 69-72, 2015.

[14] L. Min, Study on the Deformation Law of the Surface Movement under Repeated Traction in Mountainous Areas, Taiyuan University of Technology, Tai Yuan, 2012.

[15] J. Wang and L. Gao, "Surface subsidence rule of repeatedly mining under extra-thick loose aquifer," Coal Mining Technology, vol. 12, no. 2, pp. 67-69, 2007.

[16] R. Ma, Study on Deformation Law of Repeated Traction Surface under Thick Loose Layer and Pressurized Water, AnHui University of Technology, Huai Nan, 2014.

[17] L. Lei, Study on Surface Movement Law under Repeated Traction of Thick Loose Layer, AnHui University of Technology, Huai Nan, 2012.

[18] C. Yongxin, "Observation of surface rock shift law under repeated mining conditions," Mine Surveying, vol. 6, pp. 33$35,2013$.

[19] G. Weijia, S. Xizhen, and M. Yu-e, "Study on discontinuous deformation law and mechanism of repeated mining surface ground," Coal Science and Technology, vol. 41, no. 2, pp. 1-4, 2013.

[20] Z. Ming, J. Fuxing, L. Keqing, Z. Minghua, and Y. Gendi, "Study on disasters induced by key layer of repeated mining boundary," Journal of China University of Mining and Technology, vol. 45, no. 5, pp. 915-922, 2016.

[21] Y. Wang, K. Deng, and Z. Dongzhi, "The study on the character of strata subsidence during repeat mining," Journal of China Coal Society, vol. 23, no. 5, pp. 24-29, 1998.

[22] C. Xuexing, L. Weitao, and Z. Peisen, "Study on destruction rule of complex rock under thin bedrock of thick surface soil," Mining Safety and Environmental Protection, vol. 37, no. 6, pp. 20-22, 2010.

[23] L. Fengming, "Change mechanism of surface movement parameters and characteristics of moving basin under repeated mining conditions," Coal Science and Technology, vol. 26, no. 2, pp. 44-47, 1998.

[24] K. Yonghua and H. Fuchang, "Overburden failure law of fully mechanized repeated mining," Coal science and technology, vol. 1, no. 29, pp. 22-25, 2001.

[25] K. Yonghua, "The effect of various minging methods on development law of water flowing fractured zone," Journal of China Coal Society, vol. 23, no. 3, pp. 262-266, 1998.

[26] S. Xianfeng, J. Fuxing, and H. Zhu, "Research and practice on restoring production of rock burst accident working face in top slice during slice mining of extra-thick coal seams," Journal of China Coal Society, vol. 40, Supplement 1, pp. 19-26, 2015.
[27] Z. Qiang, L. Gensheng, and Z. Longhui, "Characteristics of the distribution of overlying rock fractures associated with the mining of super-thick coal seam in eastern Junggar coalfield," China Mining, vol. 27, no. 11, pp. 109-115, 2018.

[28] S. Haitao and F. Junhui, "Study on deformation characteristics of surface borehole in active coal mining area under repeated mining," Coal Science and Technology, vol. 46, no. 6, pp. 4045, 2018.

[29] T. Jianquan, L. Weitao, and M. Xu, "Study on distribution characteristics of abutment pressure in thick coal seam stratified mining based on FLAC3D," Coal Technology, vol. 37, no. 4, pp. 16-18, 2018. 